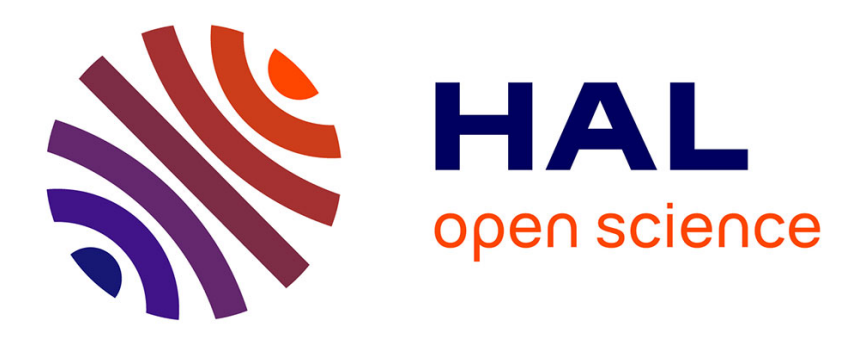

\title{
Les inscriptions des fonts baptismaux d'Hildesheim, Baptême et quaternité
}

Robert Favreau

\section{To cite this version:}

Robert Favreau. Les inscriptions des fonts baptismaux d'Hildesheim, Baptême et quaternité. Cahiers de Civilisation Médiévale, 1995, 38 (150), pp.116-140. 10.3406/ccmed.1995.2609 · halshs-03206261

\section{HAL Id: halshs-03206261 https://shs.hal.science/halshs-03206261}

Submitted on 23 Apr 2021

HAL is a multi-disciplinary open access archive for the deposit and dissemination of scientific research documents, whether they are published or not. The documents may come from teaching and research institutions in France or abroad, or from public or private research centers.
L'archive ouverte pluridisciplinaire HAL, est destinée au dépôt et à la diffusion de documents scientifiques de niveau recherche, publiés ou non, émanant des établissements d'enseignement et de recherche français ou étrangers, des laboratoires publics ou privés. 


\section{Les inscriptions des fonts baptismaux d'Hildesheim, Baptême et} quaternité

Robert Favreau

\section{Citer ce document / Cite this document :}

Favreau Robert. Les inscriptions des fonts baptismaux d'Hildesheim, Baptême et quaternité. In: Cahiers de civilisation

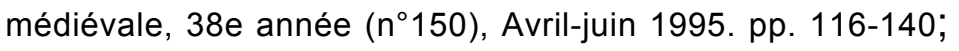

doi : https://doi.org/10.3406/ccmed.1995.2609

https://www.persee.fr/doc/ccmed_0007-9731_1995_num_38_150_2609

Fichier pdf généré le 25/03/2019 


\begin{abstract}
The baptismal font of Hildesheim cathedral is an extraordinary work by its artistic quality, the opulence of the iconographie programm and the profusion of inscriptions that inform us about the intentions of the author, his theologic, patristic, and literary culture. This elaborated programm associates the rivers of paradise with the cardinal virtues, major prophets and Gospel-writers ; the four great scenes of the bowl - donation, figures of the baptism - are in relation with the four great scenes of the lid that show the four kinds of baptism - water, martyrdom, penance, and good works. This iconography and this epigraphic commentary allow to understand better how the Church lived the sacrament of baptism during the XIIIth century.
\end{abstract}

\title{
Résumé
}

Les fonts baptismaux de la cathédrale d'Hildesheim constituent une œuvre remarquable par leur qualité artistique, la richesse du programme iconographique, l'abondance de l'accompagnement épigraphique. Les inscriptions nous éclairent sur les intentions de l'auteur, sa culture théologique, patristique, littéraire. Une construction savante met en relation fleuves du paradis, vertus cardinales, grands prophètes, évangélistes ; les quatre grandes scènes de la cuve - donation, figures du baptême - sont en rapport avec les quatre grandes scènes du couvercle qui présentent les quatre genres de baptême - l'eau, le martyre, la pénitence, les bonnes œuvres. À travers cette iconographie et son commentaire épigraphique nous pouvons mieux comprendre la façon dont l'Église, au xme s., vivait le sacrement de baptême. 
tions $^{3}$. Lne telle étude peut pourtant éclairer les intentions de l'auteur, et complète ce que l'iconographie nous dit sur le sacrement du baptème.

\section{**}

Ces fonts, larges d'environ un mètre pour deux mètres de hauteur, comprennent deux parties, la cuve et le couvercle. À la base de la cuve sont représentés les quatre fleuves du paradis, qui sont mis en relation avec les quatre vertus cardinales, les quatre grands prophètes, les quatre évangélistes. Quatre scènes figurent sur la cuve : Vierge à l'Enfant avec le donateur, passage de la mer Rouge sous la conduite de Moïse, baptême de Jésus par Jean, Josué et l'arche d'alliance passant le Jourdain pour entrer en la Terre promise. Sur le couvercle on a les quatre genres de baptème : l'eau, le martyre, la pénitence et les bonnes œuvres. Quatre vers expliquent l'iconographie de la cuve et quatre celle du couvercle [fig. a]. Il y a des relations entre couvercle et cuve. On voit donc la complexité de l'œuvre et l'extrême richesse de la composition. Si la quaternité ${ }^{4}$ structure le programme de ces fonts baptismaux, il existe des relations diverses entre chaque groupe de quatre. Le texte de synthèse sur la lèvre supérieure de la cuve :

$$
\begin{aligned}
& + \text { QUaTlOR IRRORANT PaRAdisi FllMINA MUNDUM } \\
& \text { + VIRTCTESQCE RIGANT TOTIDEM COR CRIMINE MCNDLM. } \\
& \text { "+ Les quatre fleuves du paradis irriguent le monde } \\
& \text { "+ et autant de vertus baignent le cœur pur du péché». } \\
& \text { + ORA PROPHETARUM QUE VATICINATA FLERUNT } \\
& + \text { HEC RATA SCRIPTORES EWANGELII CECINERUNT } 5 \text {. } \\
& \text { "+ Ce que les bouches des prophètes ont annoncé } \\
& \text { + les écrivains de l'évangile l'ont célébré comme accompli». }
\end{aligned}
$$

invite à une étude conjointe des fleuves et des vertus, des prophètes et des évangélistes, avant de voir ce que ces quatre groupes de quatre figures nous apprennent, ensemble, sur le sacrement du baptême.

Sur les fonts baptismaux d'Hildesheim les quatre fleuves sont présentés dans l'ordre où les cite la Genèse (II, 10-14). Chacun est accompagné d'un hexamètre qui donne et l'étymologie du nom du fleuve, et la correspondance avec la vertu cardinale qui lui est immédiatement associée. Il y a rime simple entre les hémistiches et rimes riches entre les finales des deux premiers vers, rimes riches entre les finales des deux derniers vers (versus caudali):

$$
\begin{aligned}
& \text { + os mutans Phison est PRLDenti similatus } \\
& \text { "En changeant de visage le Phison est assimilé au prudent" } \\
& \text { + Temperiem Geon TERRE DESignat hiatus } \\
& \text { "Le Géon, ouverture de la terre, désigne la tempérance" } \\
& \text { + EST velox Tigris quo rortis significatur } \\
& \text { "Rapide est le Tigre, par lequel le fort est signifié" }
\end{aligned}
$$

3. Kratz, Der Dom zu Hildesheim, I, 1840, p. 159-204: - Adolf Bertra.M, "Das eherne Taufbecken im IDom 7u Hildesheim", Zeilschrift für christlichen Kunst, XIII, 1900, col. 129-150 et 161-166; - Adolf Zri.r.er, Die romanischen Baudenkmäler von Hildesheim. Enter Berücksichtigung des einheimischen romanischen Kunstgewerbes, Berlin, 1907, p. 85-87; - V. Curt Н Авіснт, Beilräge zur. Viedersächsischen Kunstgeschichle. II. Die miltelallerliche Plaslik Hildesheims. St rasbourg. 1917 (Studien zur deutschen Kunstgeschichte, 195), p. 49-58; - Konrad Al.GERMIssFx, "Die künstlerische Gestaltung und der Ideengehalt des Hildesheimer Dom-Taufbeckens", Ensere Diözese. XXVI, 1957. p. 1-32 (j'en dois la communication à Mme Christine Wulf-Rärl., que je remercie vivement): - Janni Mulifer-Hauck. Das Taufbecken im Dom zu Hildesheim, Göttingen. 1965 (phil. Diss., dactyl.). Je n'ai pas pu voir ce dernier travail.

4. Anna C. Esmriturer. Divina qualernitas. A Preliminary Study in the Method and Application of Iisual Exegesis. Amsterdam. 1978 (ne cite pas les fonts baptismax d'Ifildesheim).

5. Cf. JÉRòm. Commentaire sur le prophète Jérémie. P.L.. 24, c. 771 : de futuro adventu luo (Christ), omnium prophelarum ora cecinerunt. 


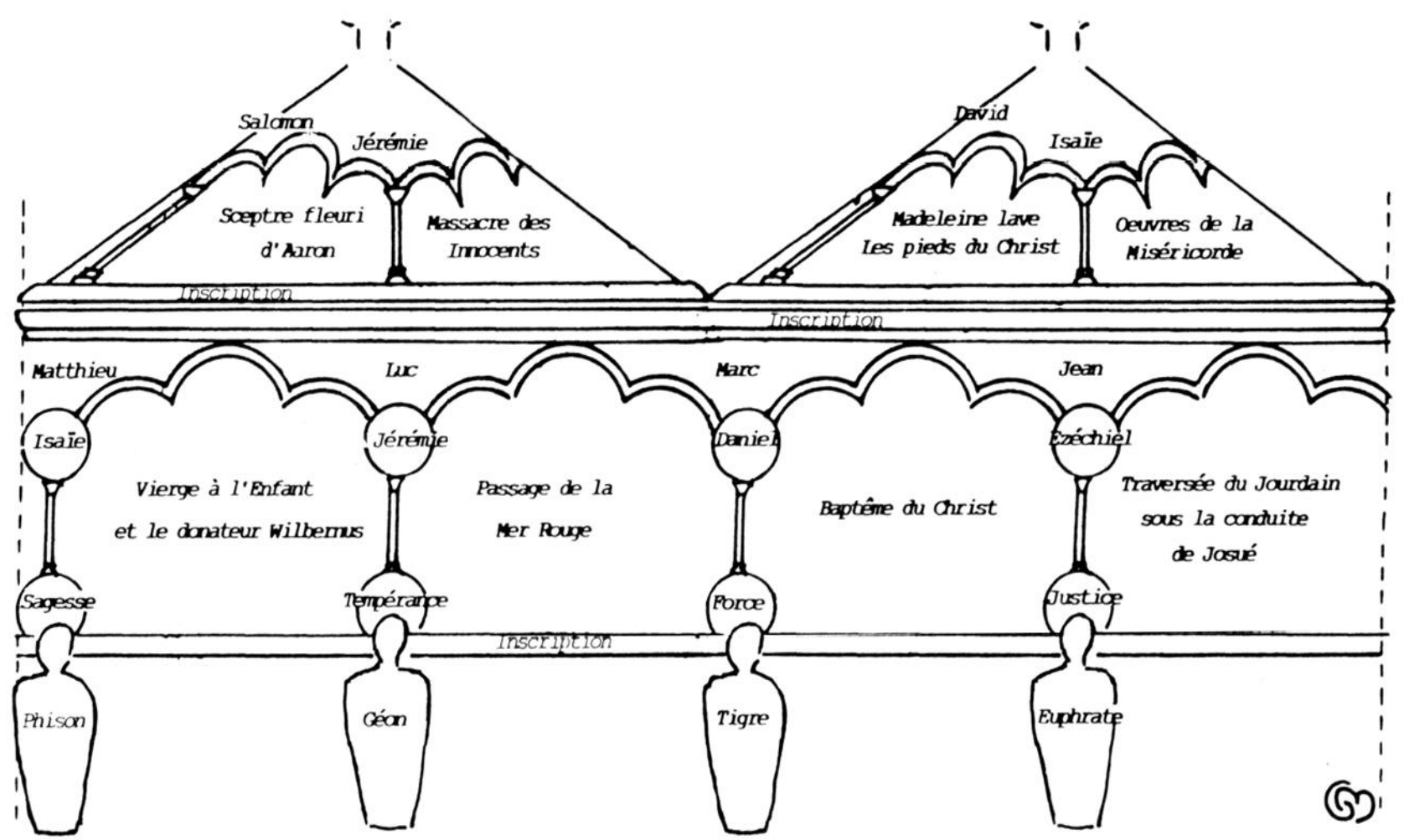

Fig. a. - Hildesheim (Basse-Saxe). Fonts baptismaux.

\section{+ FRUGIFER ELFRATES EST JUSTITIAQUE NOTATUR}

"L'Euphrate est fertile, et par lui est indiquée la justice».

Les auteurs ne donnent pas tous la même interprétation du nom de chacun des fleuves du paradis. Pour saint Ambroise ${ }^{6}$, Remi d'Auxerre ${ }^{7}$, Innocent III ${ }^{8}$, Phison veut dire "le changement dc bouche ou de visage", hoc esi oris mulalio. Dans son Livre des noms hébreux ${ }^{9}$, Jérôme donne ce sens ou encore celui de os pupillae. "la bouche de l'œil", et ce dernier sens est repris par Guibert de Nogent ${ }^{10}$, Geoffroi d'Admont ${ }^{11}$, Adam de Prémontré ${ }^{1 ?}$. Ln écrit du viI ${ }^{\mathrm{e}}$-viII ${ }^{\mathrm{e}}$ s. ${ }^{13}$ - placé longtemps sous le nom de Jérôme - avance, pour le Phison, le sens de "souffle", insufflictio, ce que retiennent Christian Druthmar, moine de Corbie ${ }^{14}$, Walafrid Strabon ${ }^{15}$ et Angelome de Luxeuil ${ }^{16}$. Raban Maur ${ }^{17}$ et Pierre le Mangeur - qui fait référence à Isidore de Séville ${ }^{18}-$ proposent le sens de caterva, la foule, ou celui d'immutatio oris. Geoffroi d'Admont, dans le sermon

6. Ambroise, De paradiso liber unus, P.L.. 1.4, c. 281.

7. Rr.mi d Acxerre, Commentarius in Genesim, P.L.. I:31, c. 61.

8. Innocent III, Sermones de sanctis, P.L., 217, c. 516 (sermon 13 pour la fète de saint Grégoire).

9. P.L.. 23. C. 779 .

10. Gurbert de Nogrext, Moralium in Genesim libri duo, P.L.. 156. c.64.

11. Groffrol D Anmoxt, Homiliae dominicales, P.L.. 17. c. 147: il donne aussi le sens doris mutalio (ibid., c. 148).

12. Adam de Prémontrí. Sermon de Noël. P.L.. 198. c. 249.

13. Exposilo quatuor evangeliorum. P.L.. 30, c. 533: le traité. du vir"-vill" s.. est peut-ètre d'un Irlandais.

14. Christian Drethumar. Expositio in Mallhaeum. P.L.. 106. c. 1:65.

15. Walafrid Strabon. Exposilio in qualuor evangelia, P.L.. 114. c. 861 (attribution douteuse).

16. Commentarius in Genesim. P.L.. 115 . C. 130 (inflatio): l'auteur indique aussi le sens d'os pupillae qu il juge meilleur.

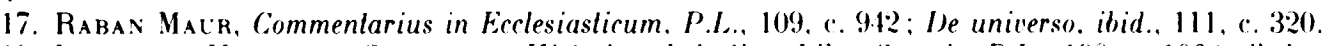

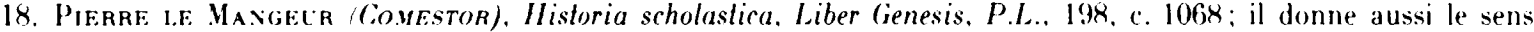
d'immutatio oris. 
où il compare les fleuves du paradis aux vertus, explique que le Phison est dit os pupillae parce que nous parlons avec la bouche, nous voyons avec l'œil, ce qui convient bien à la première vertu qui est appelée la prudence: on donne aussi pour sens oris mulatio, qui convient bien à la mème vertu, car la prudence c'est parler et voir avant de s'engager, changer de visage selon les circonstances. Le sens d'oris mulatio retenu à Hildesheim, qu'on trouve aussi dans les hymnes ${ }^{19}$. est celui qui est le plus fréquemment proposé. Pour les auteurs du moven àge le Phison correspond au Gange.

Pour le Géon, identifié au moven àge avec le . Vil, le sens donné à Hildesheim est celui-là mème que fournit saint Ambroise :", terrae hialus, l'ouverture de la terre, et après lui Pierre le Mangeur:1 et Innocent III ${ }^{2}$. Jérôme ${ }^{23}$. Raban Maur ${ }^{24}$, Guibert de Nogent ${ }^{25}$ parlent de pectus sive praeruptum. le cceur ou le précipice. Remi d'Auxerre indique praeruptio $\% 6$. Geoffroi d'Admont abruptum ${ }^{27}$.

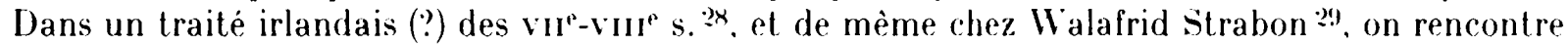
une proposition toute différente, celle de "vélocitè», qui sera généralement attribuée au Tigre. tandis qu'Angelome de Luxeuil propose "ténébreux" "3" ou mieux "fertile». ce qui sera le sens ordinaire donné au fleuve Euphrate.

De façon très générale le Tigre est appelé ainsi en raison de sa vélocité. à l'instar de l'animal de ce nom. C'est ce que risait déjà Lucain au $\mathrm{r}^{\mathrm{rr}} \mathrm{s}$. - mais il parle aussi de "l'ouverture de la terre»"31. expression réservée ordinairement au Géon par les auteurs du moven àge. C'est ce que reprennent Ambroise, Raban Maur. Remi d'Auxerre, Pierre le Mangeur. Innocent III 3?. On a la mème signification avec les auteurs qui le traduisent par la fleche rapide. dirigée contre les Assyriens, rappel de la Genèse (II, 14: Tygris ... vadit contra Assyrios). C"est le fait d'Angelome de Luxeuil, (iuibert de Nogent, Geoffroi d Admont 33 .

Tous les auteurs ci-dessus mentionnés - y compris Lucain - ont donné comme sens du nom de l'Euphrate la fertilité. fertilis, fertilitas, uberlas. Ladjectif frugifer employé par les fonts d'Hildesheim. se trouve chez Raban Maur. Remi d Auxerre. Guibert de Vogent. Geoffroi d Admont. Pierre le Mangeur. Innocent III. ainsi que dans l'hymne de Conrad Gemnicensis.

Les fleuves du paradis ont dabord été représentés comme coulant vers les quatre points cardinaux, à partir d'un monticule sur lequel se trouvait le (hrist ou l'Agneau (IV"s.), puis dès le "i"s. ils ont èté personnifiès ${ }^{34}$. Dès les premières représental ions leurs noms seront ajoutés à l'œuvre ${ }^{35}$. Au point de vue épigraphique on ne rencontre dailleurs généralement que les noms des fleuves:

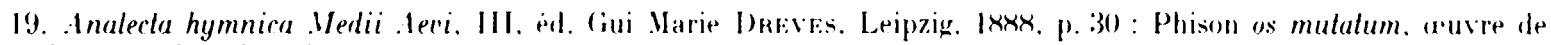
Conradus Ciemnicensis. mi-xiv"s.

20. P.L.. 1.4. c. 281 .

21. Ibid.. 198. c. 1068.

22. Ibid.. 2.17. c. 515 .

23. Ibid., 23. с. 779: Inalecta hymnica ... (n. 19). 111. p. 30 : praerupto.

24. Ibid.. 111 . c. $3: 0$.

25 . Ibid. 156) c. 66.

26. Ibid.. 131. c. 61 .

27. Ibid.. 174, c. 149.

28. Ibid.. 30. c. 533 : Geon. velocitas.

29. Ibid.. 114. c 861 (attribution douteuse).

30. Ibid.. 115, c. 130 : Cieon ... interpretalur tenebrosus ... sed melius terrae gratia vel fertilitas.

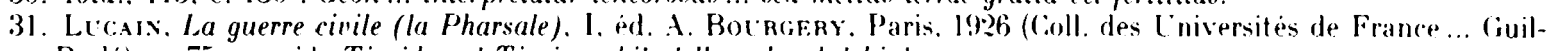
laume Bude). p. 75 : rapido Tigride; at Tigrin subito lellus absorbel hiatu.

32. P.L.. 14, c. 281: 109. c. 942, et 111. c. 3200:131, c. 61: 198. с. 1068: :17. с. 516.

33. Ibid.. 115, c. 130:156. (. $66: 174$, c. 149.

34. J. Porscrke. "Paradiesflüsse". Lexiton der chrislliche Ikonographie. III. Rome/Fribourg/Bàle/Vienne. 1971. c. 382-384 : premier exemple de personnification en Cyrénaique. On peut ajouter qu au Musée d'Alep (Svrie) sont exposées deux mosaiques du vi" s. représentant le (iéon et le Phison sous forme de femmes assises. le Phison tenant un poisson dans la main droite. et dans la main gauche un vase renverse dou l'oau söroule (noms en grece). Etude donsemble par E. Scht.f., Die Ikonographie der Paradiesflüsse. Leipzig, 19:37.

35. E. Diғна. Inscriptiones latinae christianae veteres. I. Berlin. 1925, n" 2.188. p. 184. 
Illustration non autorisée à la diffusion

Fïg. 1. - HILUESHEIM. Cathedrale fonts baptismaux.

(Cliché Bildarchin Foto Marburg. nég. 10626). 
Fig. 2. - Le fleuve du Tigre, la vertu de force, le prophète Daniel. l'évangéliste Marc. Cuve des fonts baptismaux d'Hlildesheim.

Fig. 3. - L'arche d'alliance franchit le Jourdain sous la conduite de Josué. Cuve des fonts baptismaux d'Ilildesheim.

(Clichès J. Vichand. C.E.S.C..V.. Poitiers). 
Fig. 4. - HILDESHEIM. Cathédrale, fonts baptismaux, couvercle.

Fig. 5. - Les ouvres de miséricorde. Couvercle des fonts baptismaux d'Hildesheim.

(Clichés Bildarchiv Folo Marburg, nég. 23150 et 10646). 
Fig. 6. - La vertu cardinale de la force. Cuve des fonts baptismaux d'llildesheim.

(Cliché Bildarchiv Folo Marburg, nég. 2:31:34).

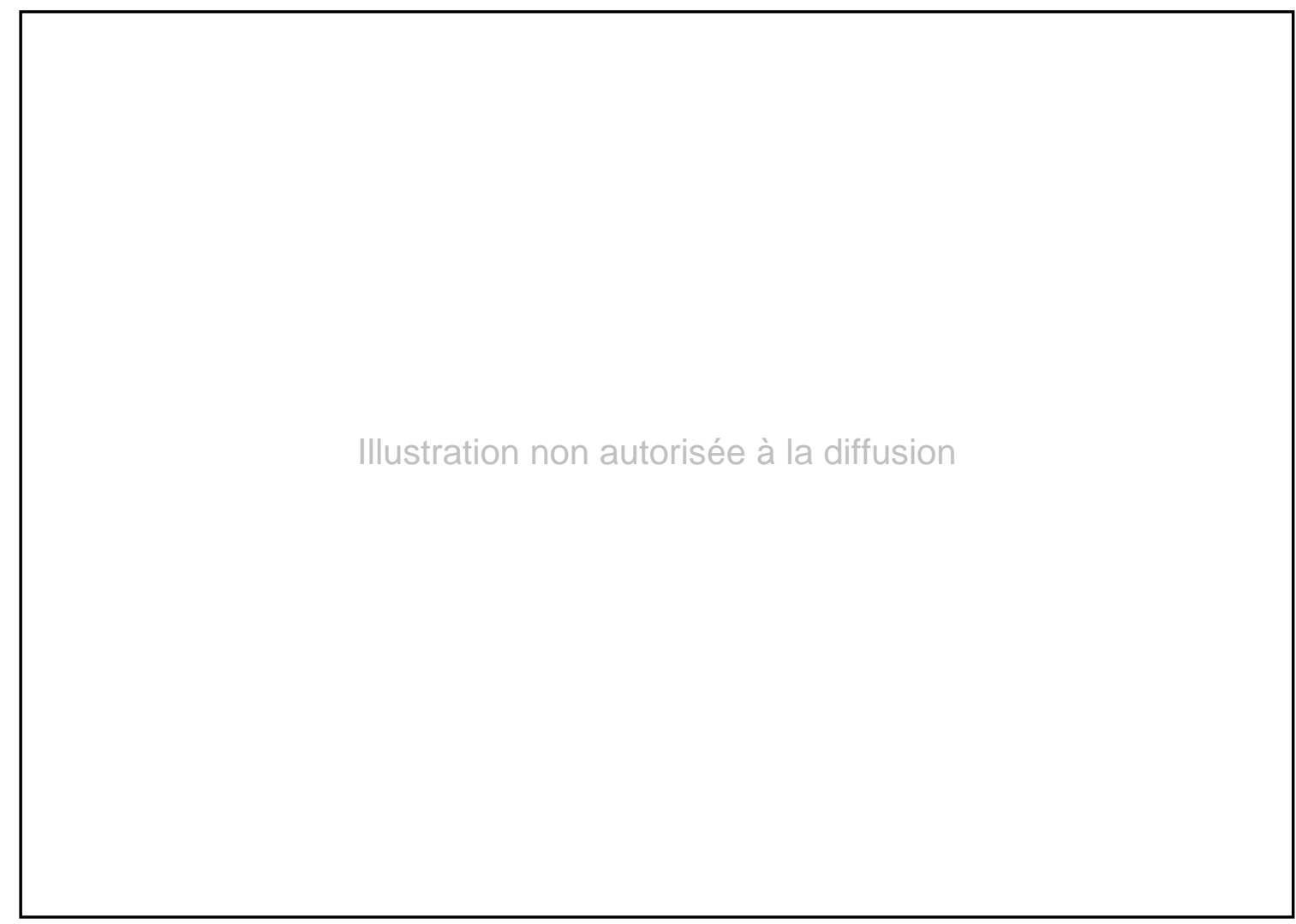

Fig. 7. - Le prophète Ézéchiel et l’évangéliste Matthieu. Cuve des fonts baptismaux dHildeshèm. (C.liche .J. Michaud. C.E.S.C...M.. Poiliers). 
mosaïques du chœur de la cathédrale d'Aoste, autel portatif de Stavelot conservé aux Musées royaux d'art et d'histoire de Bruxelles, peintures murales du porche de San Pietro al Monte à Civate, reliure d'ivoire du Schnütgen-Museum à Cologne ${ }^{36}$, mosaïque de pavement à l'ancien palais épiscopal de Die, couverture de l'évangéliaire de Notker de Liège au Musée Curtius de Liège, encensoir du trésor de la cathédrale de Trèves, pour ne prendre que des exemples propres aux seuls fleuves du paradis. La célèbre pomme de pin carolingienne, en bronze, de la cathédrale d'Aix-la-Chapelle, est plus proche des fonts baptismaux d'Hildesheim, avec les inscriptions : FERTilis eufrates, velox ut missile tygris ${ }^{37}$. Un vitrail de $1160 / 66$ à la cathédrale Saint-Patrocle de Soest constitue un autre exemple isolé où le fleuve est indiqué avec la citation exacte de la

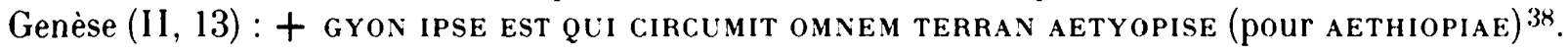

Les quatre vers consacrés aux fleuves du paradis à Hildesheim mettent ceux-ci en correspondance avec les vertus cardinales, ce que font aussi les deux premiers vers de l'inscription du bord supérieur de la cuve. Ils nous rappellent combien à l'époque romane et encore au XIII ${ }^{\mathrm{e}}$ s. on a été sensible à l'interprétation allégorique : similare, designare, significare, notare ${ }^{39}$. Aux quatre points cardinaux les personnifications des fleuves "irriguent le monde" avec leurs jarres renversées d'où l'eau s'écoule. Au-dessus de chaque fleuve est associée étroitement, dans un médaillon, une vertu cardinale, ces vertus qui à leur tour "baignent les cœurs libérés du péché".

L'origine des vertus, que déjà Ambroise appelle "cardinales" "4), se trouve dans les auteurs de l'Antiquité, Socrate et Platon, d'une part, Cicéron de l'autre. Pour Socrate la bonne conduite (eupraxis) est fondée sur les vertus de prudence, tempérance, force et justice. Platon écrit dans la République que l'État correctement fondé est parfaitement bon, et que «dès lors il est manifestement sage, courageux, tempérant et juste " ${ }^{41}$. Dans le De inventione (II, c. 53) Cicéron indique que "la vertu a quatre parties ${ }^{42}$, la prudence, la justice, la force, la tempérance", dans le De officiis (I, c. 5) il reprend la même idée : la sagesse naît de la mise en pratique des vertus de prudence, justice, force et tempérance ${ }^{43}$. Saint Augustin suit l'énumération de Cicéron dans son De diversis quaestionibus $L X X X I I I$ liber unus ${ }^{44}$, et après lui un grand nombre d'auteurs ont repris la même énumération des vertus cardinales, le plus souvent dans l'ordre même de Cicéron : Julien Pomère, Grégoire le Grand, Alcuin, Halitgarius, Raban Maur, le pseudo-Eadmer, Rupert de Deutz, Othon

36. Frauke Sternвock, Der kirchliche Prachteinband im frühen Millelalter von den Anfängen bis zum Beginn der Gothik. Berlin, 1965, n⿳31, p. 107-108 et pl. 47: - Rhin-Meuse. Art et civilisation 800-1400. Bruxelles/Cologne, 1972. p. 205. Provenance inconnue.

37. Die Inschriften des Aachener Dom, èd. Helga Gifssifpes, Wiesbaden, 1992 (Die deutschen Inschriften, 31 ). nº 13. p. 12-13. Le missile renvoie au sens de flèche, sagilla, donné au Tigre.

38. Kunst und Kullur im Weserraum 800-1600, t. II, Münster. $3^{\mathrm{e}}$ éd., 1967, no 570, p. 729-733.

39. Voir Ilenri de Lubac, Exégèse médiévale. Les qualre sens de l'Écrilure, Paris, 1959/61, 3 vol. (Théologie. Études publ. sous la dir. de la Faculté de Théologie S.J. de Lyon-Fourvières, 41-42). Innocent III met mème en rapport les fleuves du paradis et les quatre sens de l'Écriture, le Géon "désignant" l'histoire, le Phison "signifiant" l'allégorie. le Tigre "désignant" l'anagogie, l'Euphrate "signifiant" la tropologie (P.L., 217. c. 515-516). Les mots qu'il emploie, designare, signare, significare, sont ceux qu'on trouve à Hildesheim.

40. Ambroisf de Muan, Trailé sur l'évangile de s. Luc, èd. dom Gabriel Tıssor, Paris, 1956 (Sources chrètiennes, 45), p. 206 : Scimus virlutes esse quatluor cardinales, temperantiam, justitiam, prudentiam, forlitudinem. Pour Ambroise Luc ne cite que quatre béatitudes parce qu'il a en vue les quatre vertus cardinales.

41. Fuvres complètes, trad. Léon Rosin, nouv. èd.. Paris, 1953 (la Pléiade), I, p. 991. Platon reprend ensuite chacune de ces vertus.

42. Maurice Paldasse, "Brève histoire d'un schème cicéronien au moyen àge", Revue du Moyen Àge latin. I, 1945), p. 35-42; - Philippe Del.hay,, "L'enseignement de la philosophie morale au XII" s., Medieval Studies, XI. 1949, p. 77-99.

43. Cicéron, Les devoirs, èd. Maurice Testard, Paris, 1965, (Coll. des Universitès de France ... Guillaume Budé). p. $111-112$.

44. P.L., 40, c. 20-22. Il reprend la mème liste de vertus dans le lJe musica (ibid.. 32; c. 1189), le De libero arbilrio (ibid.. c. 1235), le De moribus ecclesiae catholicae (ibid., c. 1322). 
de Lucques, Conrad d'Hirschau, Honorius Augustodunensis, Pierre le Chantre, Alain de Lille ${ }^{45}$. Ces auteurs ont bien conscience de l'origine "paienne" de ces vertus et la mentionnent à diverses reprises, le pseudo-Eadmer, Halitgarius, Rupert, Honorius Augustodunensis et, plus que tout autre, Thomas d'Aquin au $\mathrm{XIII}^{\mathrm{e}} \mathrm{s}^{46}$.

L'emploi des vertus cardinales dans l'iconographie s'est précisé au $\mathrm{IX}^{\mathrm{e}} \mathrm{s}$., avec leur personnification en association avec d'éminentes personnalités, comme dans la Bible de S. Callisto où elles se tiennent derrière le trône de Charles le Chauve, sous forme de bustes dans des médaillons, comme dans la Bible de Charles de Chauve et les Évangiles de Cambrai, enfin avec des attributs particuliers, le livre pour la prudence, la balance pour la justice, la torche et le vase d'eau pour la tempérance, l'épée ou la lance et le bouclier pour la force, ce qui s'observe déjà dans les Évangiles de Cambrai (seconde moitié du $\mathrm{IX}^{\mathrm{e}} \mathrm{s}$.) ${ }^{47}$.

Dans les fonts baptismaux d'Hildesheim les quatre vertus cardinales sont représentées dans des médaillons, en buste, sous les traits de femmes couronnées, avec leurs attributs et en liaison avec les quatre fleuves du paradis. Leur ordre de présentation est celui-là même de Cicéron et de la plupart des auteurs du moyen âge. La prudence, PRUDExTIA, associée au Phison, tient dans la main droite un livre, dans la gauche un serpent et un livre sur lequel est gravé : ESTOTE PRUDENTES SICUT SERPENTES, "Soyez prudents comme des serpents", parole du Christ rapportée par Matthieu (X, 16), que citent Raban Maur et Pierre le Chantre à propos de cette vertu ${ }^{48}$. La tempérance, TEMPERANTia, associée au Géon, verse un liquide d'un vase dans un autre, c'est-àdire mélange eau et vin, changement d'attribut qui s'est opéré au cours du $\mathrm{XI}^{\mathrm{e}} \mathrm{s} .{ }^{49}$. Dans le pourtour du médaillon on lit : OMNE TULIT PUNCTUM QUi Miscuit UTILE DUlCi, «il obtient tous les suffrages celui qui unit l'utile à l'agréable", citation de l'Art poétique d'Horace ${ }^{50}$. Si on ne trouve pas cette citation dans les auteurs qui traitent de cette vertu, on peut noter qu'Hildebert de Lavardin ou plutôt sans doute Guillaume de Conches, à propos de la tempérance, cite huit autres vers d'Horace ${ }^{51}$. La force, Fortitudo [fig. 6], brandit une épée dans la main droite, tient dans la gauche un bouclier et un phylactère sur lequel on lit : VIR QLI DOMINATUR ANIMO SUO FORTIOR EST EXPUGNATORE URBIUM, "l'homme qui est maitre de soi est plus fort que celui qui conquiert les villes». Cette citation approchée du livre des Proverbes (XVI, 32) ${ }^{52}$ était trop longue et a été terminée sur le pourtour du médaillon. Dans ce seul cas le fleuve correspondant, le Tigre, est représenté par un homme en armure. La justice, Justicia, accompagne l'Euphrate et tient une balance et un phylactère sur lequel on a écrit : OMNIA IN NUMERo, MENSURA ET PONDERE PONO, "je dispose tout avec mesure, nombre et poids". Cette formule, qui existe déjà chez Sophocle,

45. Julien Pomère, P.L., 59, c. 501 et ss.; - Alcuin, ibid., 101, c. 637-638, 640, 944, 949-950; - GrÉgolre Le Grand, ibid., 76, c. 212 (Moralia in Job): - Halitgarius, ibid., 105, c. 674-676; - Raban Maur, ibid., 110 , c. 1115 1117 et 112 , c. 1253 ; - Eanmer De Cantorbery (non authentique), ibid., 159, c. 580-583; - Rupert de Deut7, ibid. 169, c. 1388-1390; - OTHON DF LucQues (attribution à Hildebert de Lavardin), ibid., 171, c. 1010-1034 et 1057-1062:Honorius Augustodunensis, ibid., 172, c. 1244 ; - Conrad n'Hirschau (attribution à Hugues de Saint-Victor), ibid., 176, c. 998; - Pierre le Chantre, ibid., 205, c. 305-308; - Alain df. Lille, ibid., 210, c. 159-162.

46. Somme théologique, Prima Secundae Partis, quaestio 61 en particulier. Thomas d'Aquin préfèrerait appeler ces vertus "principales" et réserver le nom de "cardinales" aux vertus théologales. Alcuin, Raban Maur, Rupert de Deutz. parlent aussi de virtutes principales.

47. Adolf Katzenei.f.nnogran, Allegories of the Virtues and Vices in Mediaeval Arl from Early Christian Times to the Thirleenth Cenlury, Londres, 1939 (rééd. 1968), p. 27-57; - M. Evans, "Tugenden", Lexikon der chrisllichen Ikonographie. IV, 1972, c. 364-380; - Jennifer O'Reit.y, Studies in the Iconography of the Virtues and Vices in the Middle Ages. New York/Londres, 1988, p. 112-162.

48. P.L., 112, c. $1254 ; 205$, c. 305.

49. A. Katzenellenbogen, op. cit. n. 46 , p. 55.

50. Art poétique, vers 343, dans CEuvres complètes, èd. trad. François Richard, II, Paris, 1931 (Classiques Garnier), p. $282-283$.

51. P.L.. 171, c. 1034 (La moralis philosophia serait plutòt de Guillaume de Conches). Le vers employé à Hildesheim est citè par Jean de Salisbury, dans le Metalogicus. P.L... 199, ‘. 863.

52. Proverbes, XVI. 32 : Melior est patiens viro forti; el qui dominatur animo suo, expugnatore urbium. (“est en fonction de cette citation que l'abréviation finale des fonts. URB' a été transcrite en URBILM plutôt qu'en URBIS. 
Gorgias, Platon et dans la jurisprudence romaine ${ }^{53}$, est tirée du livre de la Sagesse, avec seulement un changement dans le verbe ${ }^{54}$ et renvoie à Dieu qui fait régner l'ordre dans la création, comme le rappellent diverses citations bibliques qui utilisent les mèmes termes de mensura, pondus, numerum, ponere ${ }^{55}$, et divers auteurs chrétiens, d'Augustin ${ }^{56}$ à Alain de Lille ${ }^{57}$.

Le thème des vertus cardinales est fréquent à l'époque romane en Allemagne, en pays mosan, en Italie du Nord. Le plus souvent les vertus sont - comme c'était le cas pour les fleuves du paradis - représentées avec leurs seuls noms : autels portatifs du milieu du $\mathrm{XII}^{\mathrm{e}} \mathrm{s}$. au Musée diocésain d'Augsbourg ${ }^{58}$, d'environ 1150/60 au Kunstgewerbemuseum à Berlin ${ }^{59}$, du XII ${ }^{\mathrm{p}}$ s. au Baverisches Nationalmuseum à Munich ${ }^{60}$, antependium de l'autel de Bâle, début $\mathrm{XI}^{\mathrm{p}} \mathrm{s}$., au Musée national du moyen âge (Cluny) à Paris ${ }^{61}$, oliphant du XII ${ }^{e}$ s. transformé en reliquaire aux Musées royaux d'art et d'histoire de Bruxelles ${ }^{62}$, peintures murales à San Pietro al Monte à Civate ${ }^{63}$, croix à Fritzlar ${ }^{64}$ et couverture d'évangéliaire à Darmstadt ${ }^{65}$ où figurent aussi les quatre évangélistes, pavement de mosaique à $\mathrm{S}$. Benedetto $\mathrm{Po}_{0}{ }^{66}$, émaux du Musée de la cathédrale de Vienne ${ }^{67}$, bol de bronze du Kestner-Museum de Hanovre ${ }^{68}$. Dans quelques cas les inscriptions sont plus développées, comme à Hildesheim. C'est le cas notamment sur un pied de croix de 1170/80 environ, conservé au Kunstgewerbemuseum à Berlin où, en outre, la charité (KARITAS) est donnée comme la source des vertus cardinales : HOC EX PRINCIPIO VIRTUTCM MANAT OHIGO. HINC OMNES SLRGLNT HCNC OMNES REDECNT.

Chaque vertu cardinale a son commentaire:

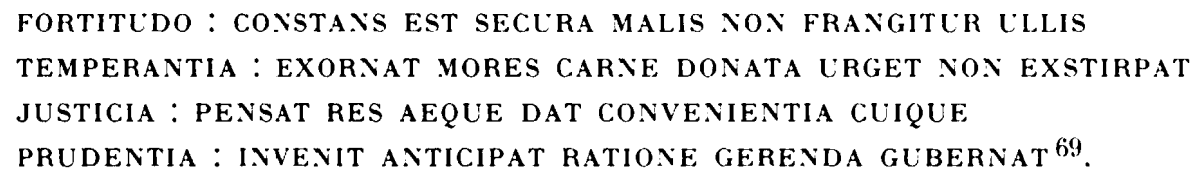

À la cathédrale de Mayence deux vers associent les vertus et leurs attributs :

QUATUOR HIC POSITA MIXTURA, LEO, DRACO, LIBRA

SIGNANT TEMPERIEM, VIM, JLS, PRLDENTER AGENTEM ${ }^{70}$.

53. II. de Lubac, Fxégèse médiévaie .... Seconde partie, 2, Paris, 1964, p. 10-11.

54. Sagesse XI, 21, : Omnia in mensura el numero el pondere disposuisti. Dans les éditions modernes, Bible de Jerusalem, T.O.B., le texte est compris dans le verset 20 et non 21 comme dans la Vulgate.

55. Esdras VIII, 34 ; Ecclésiastique I, 9; Job XXVIII, 25-26; Isaïe XL. 12.

56. P.L.. 34, c. 299-300 (De Genesi ad litleram).

57. Ibid., 210, c. 534 (.Anticlaudianus).

58. Jennifer O'REIL,Y, Studies in the Iconography of the Virlues and Vires in the Middle Ages, New York/Londres, 1988. pl. 36 a.

59. Dietrich Koтzsche, Der Welfenschalz im Berliner Kunstgewerbemuseum, Berlin, 1973, p. 70-71, n 13, pl. 19: - I)ie Inschriften der Stadt Braunschweig bis 1528. ed. Andrea Boockinans. Wiesbaden, 1993 (I)ie deutschen Inschriften. 35). p. 19-20, n"12.

60. A. Katzenellanbogen, op. cit. n. 47, pl. 28.

61. P. E. Schram et Fl. Mё тherich. Denkmale der deutschen Könige und Kaiser ... 768-1250. Nunich. 1962. p. 166. $\mathrm{n}^{\circ} 138$ et lig. 138 , p. $359-361$.

62. Art chrétien jusqu'à la fin du Moyen age. Catalogue. par A. Javsen. Bruxelles. 1964 (Musées royaux d'art et d'histoire), p. 32 .

63. Sandro Chifrici, Lombardie romane. La-Pierre-qui-Vire. 1978. p. 221 et pl. 72.

64. Peter Springer, Kreuzfüsse. Ikonographie und Typologie eines hochmiltelalterlichen Geräles. Berlin. 1981 (Bronzegeräte des Mittelalters, 3), p. 87-91. n* 8:-Die Inschriften der Stadt Fritzlar, éd. Theodor Nibofrol E1.t, Munich. 197.t (I)ie deutschen Inschriften. 14), p. 7-8. n" 6.

65. Rhin-.Meuse. Art et civilisation 800-1400. op. cit. n. 36. p. 259 (Darmstadt. Hessisches Landesmuseum).

66. A. Kingsley Porter. Lombard Architeclure. III, New Haven/Londres/(0xford, 1917. p. 361.

67. Ornamenta ecclesiae. Kunst und Kunstler der Romanik ... Cologne. 1985, 1. p. 296-297. Plaques émaillées aver une ou deux vertus cardinales, au Musée de l'Ermitage a Saint-Pétersbourg. au Victoria and Albert Museum a Londres. 68. Josepha Wfitzmaxi-Find fir. Romanische gravierie Bronzeschalen. Berlin. 1981. p. 35-37. n" 35.

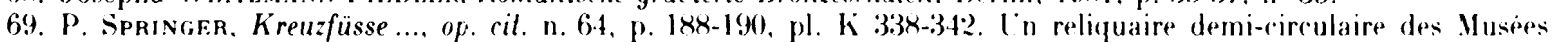
rovaux de Bruxelles représente de mème les vertus. avec au centre vajon hoнiм karitas.

70. Die Inschriften der Stadt Main: .... èd. V. AkFss. Stuttgart. 1958 (Die deutschen Inschriften, 2), p. 26, n"19. 
Sur six plaques du musée de Darmstadt, d'environ $1170 / 80$, sont représentées six vertus, dont la force et la tempérance, chacune avec un verset de l'Ecclésiastique ${ }^{71}$. Sur le reliquaire de SaintGhislan les vertus, dont la tempérance, portent chacune le texte d'un des dix commandements (Temperaxtia : Non concupisces rem proximi tui) ${ }^{72}$. Nombreuses sont, par ailleurs, dans les manuscrits les représentations des vertus cardinales ${ }^{73}$. "Des quatre principales vertus, la prudence, la justice, la force, la tempérance, naît tout l'ordre et série des vertus; elles sont nécessaires à tout homme chrétien, parce que autrement il est dominé par la pestilentielle maladie des vices". L'inscription des fonts d'Hildesheim consacrée aux vertus ne dit pas autre chose que ce qu'avançait Raban Maur au IX ${ }^{\circ}{ }^{74}$.

Sur le bord supérieur de la cuve deux vers rapprochent les quatre grands prophètes des quatre évangélistes : les premiers ont annoncé ce que les seconds montrent accompli. Ce rapprochement est particulièrement suggestif de la relation entre Ancien et Nouveau Testament ${ }^{75}$. On le trouve fortement souligné dans la production de l'École de Tours à l'époque carolingienne : dans la Bible de Bamberg avec seulement les noms des prophètes et des évangélistes, dans la Bible de Vivien et dans la Bible de Grandval avec les noms et deux vers :

\section{Rex mical aethereus condigne sive prophelae \\ Hic evangelicae qualluor atque lubae,}

dans les évangéliaires d'Arnaud à Nancy et de Lothaire à Paris, avec le texte :

\section{Qualtuor hic rutilant uno de fonte fluentes Matlhei, Marci, Lucae libri atque Johannes.}

Dans chaque composition le Christ ou l'agneau est au centre ${ }^{76}$. "Nous devons savoir que presque les mèmes mots qui sont dans l'Évangile nous les lisons dans le prophète" ${ }^{77}$.

Si l'inscription des fonts baptismaux d'Hildesheim nous montre que l'auteur du programme a, d'abord, voulu insister sur la "concordance" entre prophètes et évangélistes, les textes qui accompagnent les huit figures sont d'une interprétation moins évidente que ceux qui ont été joints aux fleuves du paradis et aux vertus cardinales. On observera d'entrée que l'on n'a pas suivi l'ordre canonique des prophètes et des évangélistes, Daniel étant ici présenté avant Ézéchiel, et Luc avant Marc. D'Isaie on a choisi le premier verset du chapitre XI : EgREdiETLR virga de RADICE JESSE, "Ln rameau sortira de la souche de Jessé», qui est un des versets les plus souvent cités du prophète et annonce l'Incarnation. Il est dès lors normal qu' Isaïe soit associé à Matthieu, représenté par son symbole, l'homme, parce que son Évangile commence par donner la généalogie du Christ [fig. 7]. Pour Matthieu on a : ipse salvem faciet popully sucm a peccatis eorum (I, 21), "c'est lui qui sauvera son peuple de ses péchés». Le verset qui renvoie au baptème est une allusion à l'étymologie du nom de Jésus, "le Seigneur sauve», et a un lien avec l'Incarnation, car la phrase qui précède la citation est : "elle enfantera un fils auquel tu donneras le nom de Jésus,

71. Die Sammlungen des Baron von Hüpschen. Ein Kölner Kunstkabinelt um 1800, Cologne/Darmstadt, $1964 . n^{\circ} 45$. fig. 48.

72. Ornamenta ecclesia .... op. cil. n. 67,1, p. $73-74$ et 78 .

73. Exemples avec textes : lectionnaire de l'archevèque de Cólogne Frédèric I"r. évangéliaire d'Henri le Lion (A. KaT7.FNELI. En BogEN, op. cil. n. 46, p. 32-33), ou, au trésor de la cathédrale d'Hildesheim, le sacramentaire de Ratmann (.Merlis Stahi. el Helmar Harter. Die Handschriften im Domschalz zu Hildesheim, Wiesbaden, 1984. p. 117. n 37 ).

74. P.L., 112, c. 1253 .

75. M.-L. David-Davel, "Prophètes (iconographie)", Catholicisme, 11. Paris, 1988, c. 1277.

76. Nie karolingischen Miniaturen im Auftrage des deutschen Vereins für Kunstwissenschaft, par Wilhelm KöнI.FR. I. Die Schule von Tours. Berlin, 1963, pl. 35, c. 52, 56, 73, 98.

77. JÉròm F. Commentaire sur Michée, P.L., 25, c. 1222 : Scire autem debemus quod in Evangelio prope eadem nerha sint. quae nunc legimus in propheta. el juxta contextum illius loci alterum habere sensum, quae utrum assumpla sint de propheta, an propria auctoritate praecepta. nosse Domini est, qui in prophetis et in evangeliis loculus est. Cf. aussi JÉrỏmf. Commentaire sur le prophète Jérémie. ibid., 24, c. 758 : quod omnes prophetae in typum Iomini Salvatoris pleraque gesserint. 
car c'est lui qui sauvera...". À droite d'Isaïe et Matthieu se trouve la Vierge à l'Enfant avec le donateur.

Jérémie vient ensuite avec l'affirmation que Jésus sera "roi et règnera avec sagesse" : REGNABIT REX ET SAPIENS ERIT (XXIII, 5). Là aussi il faut penser à ce qui précède : «Des jours viennent où je susciterai pour David un rejeton légitime», ce qui annonce plus clairement encore le texte de Luc : Dabit illi domives sedem david patris eJcs (I, 32), "le Seigneur lui donnera le siège de David son père». Dans le verset précédent $(I, 31)$, on retrouve le texte de Matthieu I, 21 : "tu enfanteras un fils et tu lui donneras le nom de Jésus». Les textes de Jérémie et de Luc semblent plutôt se rapporter à la Vierge à l'Enfant qu'au passage de la mer Rouge qui suit.

Le texte du prophète Daniel évoque aussi le pouvoir de Jésus. "[Il lui a donné pouvoir, honneur et règne] et tous les peuples, nations et langues le serviront ". OMNES POPULI, TRIBCS ET IINGLE IPSI SERviext (VII, 14). Le texte qui accompagne le lion de Marc est évidemment en rapport avec le baptême de Jésus par Jean Baptiste : IPSE vos baPTIZabIT IN SPIRITC SANCTO ET IGNE, «il vous baptisera dans l'Esprit Saint et le Feu ". Ce n'est pas une citation de Marc (I, 8 : ille vero baptizabil vos Spiritu sancto), mais le texte mème de Matthieu (III, 11) ou de Luc (III, 16). Peut-être l'auteur a-t-il été ici entraîné par le fait que dans l'ordre logique l'évangéliste, à cette place, aurait dù ètre Luc. Pourquoi a-t-on choisi un texte de Daniel sur la grandeur du Christ? Jean Bapliste indique à ceux qui l'interrogent sur la sorte de baptême qu'il délivre : "celui qui vient après moi est plus fort que moi" (Matthieu III, 11), et au moment de l'Ascension le Christ dit aux apôtres : "Tout pouvoir m’a été donné au ciel et sur la terre. Allez, de toutes les nations faites des disciples, les baptisant au nom du Père et du Fils et du Saint Esprit " (Matthieu XXVIII, 18-19). Peut-être aussi l'auteur a-t-il recherché ici une construction verticale, mettant en relation le fleuve du Tigre (le seul représenté armé), la force, Daniel (le seul prophète dont le nom est précédé d'une croix), et le lion de Marc [fig. 2], hypothèse qui expliquerait aussi le classement de Marc après Luc.

Le texte du dernier grand prophète, Ézéchiel, peut sembler étrange au vu du programme de ces fonts : similitido animalium et hic aspectus eorem ( 1,5 : similitudo quatuor animalium ...), "[au centre je discernais] quelque chose comme quatre animaux dont voici l'aspect». De l'Évangile de Jean on a retenu l'affirmation du prologue : verbum caro factum est (I, 14), "le Verbe s'est fait chair", qui résume l'histoire du salut, ce prologue si riche qui a fait attribuer à son auteur le symbole de l'aigle qui monte au plus haut du ciel. Ézéchiel a commencé son livre en se disant "au milieu des déportés, près du fleuve Kebar" (I, 1), en lequel on voit un canal latéral à l'Euphrate ${ }^{78}$. Mais c'est plutôt sans doute parce qu'on avait choisi d'évoquer sa vision des quatre animaux qu'on l'a placé après Daniel, pour qu'il soit associé à Jean qui, dans l'Apocalypse (IV. 6-9), reprend et explicite la vision d'Ézéchiel, ce qui conduira les Pères, à partir d'Irénée de Lỵon, à appliquer aux évangélistes la symbolique des quatre animaux. Dès lors on peut penser que l'auteur a voulu ici renvoyer au superbe commentaire qu'a donné de la vision d'Ézéchiel et de la vision de l'A pocalypse Grégoire le Grand dans ses homélies sur Ézéchiel et ses Moralia in Job : «le Christ est homme en naissant, bœuf en mourant, lion en ressuscitant, aigle en montant aux cieux", homo nascendo, vilulus moriendo, leo surgendo, aquila ad caelos ascendendo ${ }^{79}$, ce qui est évoquer l'Incarnation, la Passion, la Résurrection et l'Ascension. Cette interprétation justifie le passage de Marc après Luc, puisque la Passion précéde la Résurrection, et le glissement d'Ézéchiel après Daniel. Le fleuve sort du paradis en quatre tètes, et l'Évangile irrigue le monde "en quatre tètes, écrit Rupert de Deutz, c'est-à-dire dans les quatre sacrements nécessaires du salut, qui sont l'incarnation, la passion, la résurrection et l'ascension. Les eaux de la vie sont divisées en ces

78. On n'a pas recherche une correspondance précise avec le bas de la cuve car alors il aurait fallu associer Ézéchiel a la

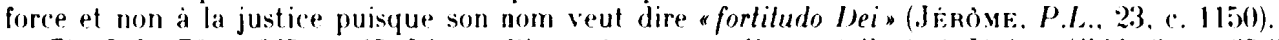

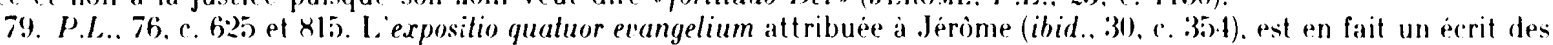
vi"-vil" s. : Dominus .Jesus (Christus totum implevit, homo nascendo. vitulus immolando, deo surgendo, aquila ascendendo. 
quatre têtes, c'est-à-dire en ces principaux sacrements, parce que toutes les Écritures tendent subtilement à ces quatre têtes, en les appelant la face de l'homme, la face du bœuf, la face du lion et la face de l'aigle" ${ }^{80}$. Le Dialogus de laudibus sanctae crucis, manuscrit du dernier quart du $\mathrm{XII}^{\circ}$ s., qui vient de l'abbaye bénédictine Saint-Emmeran de Ratisbonne (Regensburg), comporte en son folio $5 \mathrm{v}^{\circ}$ un schéma très complexe de la quaternité du paradis. Au centre le paradis tient dans un médaillon un agneau nimbé; partent de ce médaillon les quatre fleuves du paradis, les quatre vertus cardinales, les quatre évangélistes représentés par leurs symboles, sans les noms mais avec l'indication qu'ils représentent l'Incarnation (carne verus), la Passion (moritur), la Résurrection (mors mortis), l'Ascension (ad alla levalur): sont jointes aux fleuves les figures des quatre docteurs, Ambroise, Augustin. Jérôme, Grégoire ${ }^{81}$. Ln manuscrit de Zwiefalten, d'environ 1140/50, comporte la représentation de la Croix au centre de laquelle est l'Agneau nimbé ; aux quatre branches sont les noms des quatre fleuves, aux quatre angles du folio les quatre vertus cardinales, de chaque côté des bras de la croix les quatre évangélistes. Tout autour on peut lire : Quatuor virtutes cardinales, in quibus omnes virtutes velut janua in cardine pendent et IIII flumina paradisi figuram tenent IIII evangelistarum, qui lamquam columne celi sustentant orbem terrarum et sua doctrina replent et rigant universum mundum. Ex eorum quippe scriptis seplem seplem signacula libri reseranlur, id est Christi incarnatio, baptismus, passio, descensio ad infernos, resurrecti[o], ascensio, Sancti Spiritus descensio ${ }^{82}$.

Cette savante construction en quatre groupes de quatre personnages ou figures qui structurent la composition de l'iconographie de ces fonts a un premier enseignement à nous donner sur le sacrement du baptême, et le fait que les quatre vers du bord supérieur de la cuve ne traitent que d'eux justifie qu'on leur réserve un examen particulier.

D'abord il est clair qu'il y a une correspondance générale étroite entre fleuves du paradis, vertus cardinales et évangélistes. "La fontaine du paradis, c'est le Christ, les quatre fleuves qui en naissent désignent les vertus cardinales" écrit saint Ambroise ${ }^{83}$. "Les quatre fleuves qui procèdent de la fontaine du paradis, et les quatre Évangiles..., et les animaux ailés avec quatre faces recommandent fortement la dignité du chiffre quatre; et c'est pourquoi nous devons considérer avec attention ces vertus qui contiennent tant de perfection en ce nombre et confèrent une si grande sainteté à l'âme chrétienne" (Julien Pomère) ${ }^{84}$. "Le fleuve qui sort du paradis porte l'image du Christ, coulant de la source paternelle, qui irrigue toute son Église par le verbe de la prédication et le don du baptème. Les quatre fleuves du paradis sont les quatre Évangiles envoyés pour la prédication à toutes les nations" (Isidore de Séville) ${ }^{85}$. Raban Maur dans son De laudibus sanctae crucis, montre que les quatre fleuves du paradis irriguent toute la terre à partir de la seule vraie fontaine qui est le Christ et représentent les quatre Évangiles qui par la bouche des prédicateurs irriguent le monde entier pour faire germer les fruits des vertus ${ }^{86}$. Moine de Fulda, Walafrid

80. Repert DE IDETT. Commentariorum in Cantica canticorum liber IV. P.L.. 168. c. 889.

81. Munich, Bayeris.he Staatsbibliothek, Clm 14159. Cf. A. C. EsmeiJfr. Divina quaternitas ..., op. cit. n. 4, fig. 55 b et 57 b et Elisabeth Ki.r.m. Die romanischen Handschriften der Bayerischen Staatsbibliothek, 1. Die Bistümer Regensburg. Passau und Salzburg. Textband, Wiesbaden, 1980 (Katalog der illuminierten Ilandschriften der Bayerischen Staatsbibliothek in München, 3. Die romanischen Handschriften. Teil 1), no 35. p. 36:- Anton Lfg.ver. Deutsche Kunsl der Romanik, Munich, 1982, pl. 489; - Philippe Verdier, "Dominus potens in praelio", Wallraf-Richarlz Jahrbuch, XLIII, 1982. p. 73. fig. 47.

82. Die romanischen IIandschriften der Württembergischen Landesbibliothek Sultgart. 1. Provenienz Zwiefalten, par Sigrid voN Borries-Schlitex, Stuttgart. 1987 (Katalog der illuminierten Handschriften der Württembergischen Landesbibliothek Stuttgart, 2. Die romanischen Handschriften), p. 91-95, n" 61, Codex brev. 128, Kollectar. et fig. 209.

8:3. P.L.. 14, c. 279 (lie paradiso).

84. Julis Pomsre. Je Vita contemplativa libri tres, P.L.. 59. c. 501.

85. P.L., 83, c. 216.

86. Ibid., 107, c. 210. 
Strabon dit de même : "les quatre fleuves qui coulent d'une seule source, à savoir le Christ, signifient les quatre évangélistes. Ils irriguent le monde c'est-à-dire l'Église, et signifient les quatre vertus... De même que les quatre fleuves irriguent le paradis, ainsi ces quatre vertus irriguent notre cœur" ${ }^{87}$. "D'une seule et singulière fontaine coulent les quatre fleuves, et de cette même fontaine procèdent la doctrine des quatre Évangiles et les quatre vertus par lesquelles brille l'Église", renchérit Remi d'Auxerre ${ }^{88}$. Le rapprochement est parfois fait seulement entre fleuves et évangélistes: "Les quatre fleuves du paradis sont les quatre Évangiles adressés à toutes les nations" dit Isidore de Séville ${ }^{89}$. "Les quatre fleuves signifient les quatre Évangiles qui ont leur origine dans le Seigneur Jésus Christ, par lesquels il irrigue son Église qui est figurée par le paradis", commente Angelome de Luxeuil ${ }^{90}$. Ce rapprochement est particulièrement en vogue à l'époque carolingienne car on le trouve encore dans les Libri carolini ${ }^{91}$, chez l'évêque de Cambrai Halitgarius ${ }^{92}$, chez Christian Drutmar, moine de Corbie ${ }^{93}$, chez Haymon d'Auxerre ${ }^{94}$.

Le programme des fonts baptismaux d'Hildesheim convient parfaitement à la fonction des fonts, l'administration du sacrement de baptême. "L'eau n'a pas en elle-même une vertu magique. Il faut qu'elle soit fécondée par l'Esprit, sanctifiée par le Christ qui y est descendu lors du baptême", écrit saint Ambroise ${ }^{95}$. Le Christ est la "fontaine de vie» à partir de laquelle les fleuves du paradis, les Évangiles irriguent le monde. À Hildesheim le Christ est notamment signifié par les symboles des évangélistes, figures de sa nativité, de sa mort, de sa résurrection, de son ascension, ainsi que par les grandes scènes de la cuve. Sixte III, pape de 432 à 440 , a fait dresser les huit colonnes de porphyre du baptistère Saint-Jean du Latran et a fait graver sur l'entablement :

\section{FONS HIC EST VITAE QUI TOTUM DILUIT ORBEM \\ SUMENS DE CHRISTI VULNERE PRINCIPICM \\ "C'est ici la source de vie qui a lavé la terre entière \\ tirant son origine de la blessure du Christ" ${ }^{96}$.}

Sur le bord de la cuve baptismale de l'église Saint-Germain de Tirlemont, de 1149, on lit de même :

\section{CHRISTUS FONS VITE FONTEM SIC CONDIDIT ISTUM}

UT NISI PER MEDIUM MISERI REDEAMUS AD IPSUM

"Le Christ, fontaine de vie, a ainsi fondé cette fontaine

afin que nous qui sommes misérables nous revenions à Lui par ce moyen " ${ }^{97}$.

"Le baptême est à la fois mort et résurrection. La fontaine est comme un tombeau où l'homme descend pour satisfaire à la sentence portée contre le péché. Mais il est enseveli avec le Christ pour ressusciter avec Lui. Le baptême est donc, avant d'être vie, mort avec le Christ", poursuit

87. Ibid., 114, c. 861 (attribution douteuse).

88. Ibid.. 131, c. 62

89. Ibid., 73, c. 216.

90. Ibid., 115 , c. 130

91. Ibid., 98, c. 1183 : Quatuor flumina de uno paradisi fonte emananlia, el quatuor evangelia de fonte lucis et origine bonitatis procedentia, et quatuor virlutes, prudentia videlicet, forlitudo, justitia seu temperantia humanam vilam honestissimis regulis moderantes esse describuntur.

92. Ibid., 105, c. 676.

93. Ibid. 106 , c. 1265 .

94. Ibid., 117, c. 1203 (attribué dans la P.L. à Haymon d'Halberstadt) : Quaternarius consecratus esi propter quatuor flumina paradisi, vel qualuor libros Evangelii, seu etiam propter qualuor mundi parles vel qualuor virlutes principales.

95. Ambroise de Milan, Des sacrements, Des mystères, éd. dom Bernard Botte, Paris, 1961 (Sources chrétiennes, 25 bis), p. 35 .

96. Philippe Lauer, Le palais du Latran, étude historique el archéologique, Paris, 1911, p. 45; - Th. Ca Melot, Spiritualité du baptême. Paris, 1960 (Lex orandi. 30), p. 11.

97. Rhin-Meuse, Art et civilisation 800-1400, op. cit. n. 36, p. 70 : la cuve baptismale est aux Musées rovaux d'art et d'histoire de Bruxelles. Sur une reliure du milieu du xil ${ }^{e}$ s. à la Württembergische Landesbibliothek de Stuttgart on trouve aussi l'inscription : SITIE.NTES HIC PROPERATE FONS EGO SLM VITE. 
Ambroise de Milan ${ }^{98}$. L'apôtre Paul écrivait déjà : «Ensevelis avec Lui lors du baptême, vous en êtes aussi ressuscités avec Lui" (Colossiens II, 12), et Pierre exhortait chacun à se faire baptiser au nom de Jésus Christ "pour la rémission de ses péchés" (Actes II, 36-38). Les grands docteurs de l'Église d'Orient, Basile, Grégoire de Nysse, Grégoire de Nazianze, Jean Chrysostome, reprennent tous la même affirmation : le baptême est mort du péché, nouvelle naissance de l'âme ${ }^{99}$. In remissionem peccatorum, ... in vilam aeternam, "pour la rémission des péchés, ... pour la vie éternelle", ad creandos novos populos quos tibi fons baptismatis parturil, "pour créer les nouveaux peuples que la fontaine du baptême t'a enfantés", dit la liturgie de la benedictio fontis le samedi saint ${ }^{100}$. Cette idée de la rémission des péchés est clairement exprimée par l'inscription du bord de la cuve d'Hildesheim, qui note que "le cœur pur du péché" peut se consacrer aux vertus, et par le texte du prophète Isaïe : "c'est Lui qui sauvera son peuple de ses péchés». Au Credo le chrétien affirme : "Je crois en un seul baptême pour le pardon des péchés". Tout le contexte liturgique et patristique, et la symbolique de l'eau mettent cette rémission des péchés au premier rang des fruits du baptême. "Le pêcheur se plonge dans la fontaine sacrée pour se purifier, et l'eau en fait un homme nouveau" dit l'inscription de Sixte III au baptistère du Latran. "Purifie, ô Dieu, par l'eau du saint baptême, la faute qu'a commise le premier homme avec le fruit [défendu]", lisait-on sur les fonts de Saint-Gangolf de Trèves ${ }^{101}$, et de même on avait inscrit sur les fonts de Veyga en Espagne en 1128 : HIC LAVANTLR SORDIDI, HIC CURANTUR MORVIDI ET SANANTUR INFIRMi ${ }^{102}$. Sur les fonts baptismaux de la cathédrale de Merseburg, où sont représentés apôtres, prophètes et fleuves du paradis, on a l'inscription :

\author{
+ HOS DEUS EMLNDA quOS ISTIC ABLUit UNDA \\ FIAT UT INTERIUS QUOD FIT ET EXTERIUS \\ "Dieu, purifie ceux qu'ici l'eau a lavés \\ Que ce qui leur est arrivé extérieurement leur arrive intérieurement" ${ }^{103}$.
}

L'inscription des fonts baptismaux de Magneville, du XII ${ }^{\mathrm{e}}$ s., dit de même "que la fontaine sacrée purifie entièrement, l'eau de la fontaine extérieurement, l'Esprit intérieurement" " ${ }^{104}$, et d'après l'inscription des fonts baptismaux de Fresnada de la Sierra en 1225, "c'est le péché originel lui-même qui est enlevé par l'eau du baptême " 105 . Pour celui qui est ainsi lavé de tout péché, le baptême est une nouvelle naissance - le baptisé est "rené» à la fontaine du baptême 106 - le fait "passer de la faute à la grâce" (Ambroise), le rend capable de s'attacher désormais aux quatre vertus cardinales dont le Christ est "la source et le principe" (Jérôme) ${ }^{107}$.

98. Ambroise df, Mulan, Des sacrements, Des mystères, op. cit. n. 95. p. 35.

99. Camriot, Spiritualité du baptême, op. cit. n. 96, p. 13, 14, 111, 126.

100. Le sacramentaire grégorien, ses principales formes d'après les plus anciens manuscrits. I. Le sacramentaire, le supplément d'Aniane, éd. Jean Drshusses, Fribourg, 1971 (Spicilegium Friburgense, 16), p. 185, 188.

101. F.X. Kraus, Die christlichen Inschriften der Rheinlande von der Mitte des achten bis zur. Mitte des dreizehnten Jahrhunderts, Fribourg/Leipzig, 1894, p. 174, $\mathrm{n}^{\circ} 361$ ( $\mathrm{xII}^{\mathrm{e}} \mathrm{s}$.).

102. España sagrada, éd. Manuel Risco, t. 41, Madrid, 1798, p. 17.

103. Die Inschriften der Stadt Merseburg, éd. Peter Raмm et Ernst Schurert, Berlin/Stuttgart, 1968 (Die deutschen Inschriften, 11), p. 12-14, $\mathrm{n}^{\circ} 9$.

104. Arcisse de Caumont, Cours d'anliquilés monumentales, VI, 1841, p. 61, et atlas, p. xxvin bis.

105. José Perez. Carmona, Arquiteclura y escultura romanicas en la provincia de Burgos, Burgos, 1959. p. 50 :

MATRIS PECCATUM NOBIS AB ORIGINE NATLM

HOC: EST ABLATUM PE.NITUS QUOQLE FONTE FUGATLM.

106. IIC BAPTIZATL M BAPTISMI FONTE RE. ATTLM ..., fonts baptismaux de Legnica (Liegnitz), xII" s. (Paul KNotei, "Die schlesischen Inschriften des Mittelalters", Milleilungen der schlesischen Ciesellschaft für Folkskunde. XXXIXXXII, 1931. p. 235).

107. Jéròmf, Commentariorum in Isaiam prophetam libri duodeviginti. P.L., 24, c. 145 : "Chrislus ... cunclarum virlutum fons sit alque principium*. 
Dans le programme d'Hildesheim, fleuves, vertus et évangélistes forment un ensemble parfaitement cohérent, que l'on rencontrait aussi sur le retable de saint Remacle à Stavelot, vers $1135^{108}$, et qui a été retenu sur le calice de Trzemeszno de 1180/90109. L'originalité d'Hildesheim est d'avoir joint à ce programme déjà complexe les quatre grands prophètes, ce qu'on ne trouve pas dans d'autres ceuvres. Peut-être l'auteur du programme a-t-il voulu de la sorte insister sur la quaternité, quadragenarius numerus in Scriptura sacra multimoda ratione habelur perfectus, écrivait Haymon d'Auxerre au IX ${ }^{\mathrm{e}}$ s. ${ }^{110}$.

La structure verticale de quatre fois quatre figures isole sur la cuve quatre grandes scènes. La première, qui part du premier fleuve, de la première vertu, du premier grand prophète et du premier évangéliste est la scène où est représenté le donateur qui offre son œuvre à la Vierge à l'Enfant, entre deux évêques:

WILBERNLS VENIE SPE DAT IACDIQUE MARIE

HOC DECUS ECCLESIE SUSCIPE CHRISTE PIE

"Wilbernus donne cette parure à l'église, avec l'espoir du pardon et en louange à Marie; reçois-lé, ô Christ, en ta piété».

On trouve, dans la première moitié du xıII ${ }^{\mathrm{e}}$ s., un Wilbernus qui offre des fonts baptismaux à la cathédrale Saint-Pierre d'Osnabrück :

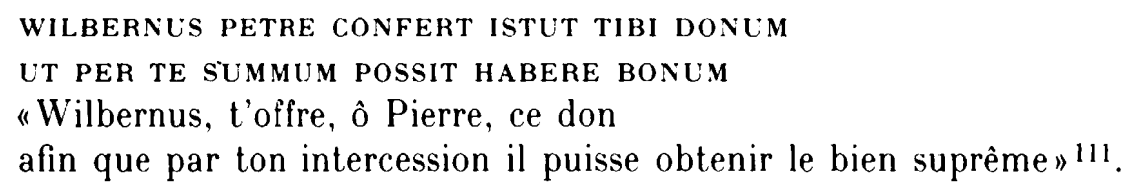

On a soutenu que ce Wilbernus pouvait être identifié à Wilbernus, chanoine de Goslar, ou à Wilbrand, comte de Oldenburg-Wildeshausen que l'on connaît à Hildesheim puis à Osnabrück de 1219 à 1226, mais il semble plus sage de penser à un membre du chapitre cathédral d'Hildesheim puis/et d'Osnabrück, peut-être plutôt membre des deux chapitres, ce qui justifierait la présence de deux évêques. On ne trouve dans les sources le nom de Wilbernus qu'une seule fois, dans un nécrologe d'Osnabrück du XIII ${ }^{\mathrm{e}}$ s., à la date du 22 mai. L'inscription de donation forme à Hildesheim un distique élégiaque léonin riche en versus unisoni (mêmes rimes aux hémistiches et aux finales), à Osnabrück un distique élégiaque, où le deuxième vers est léonin, et où les deux syllabes finales sont les mêmes (versus caudati). Dans le premier vers des fonts d'Hildesheim le donateur demande le pardon de ses péchés et offre l'œuvre à Marie, patronne de la cathédrale; en fin de deuxième vers il demande au Christ d'accepter son offrande. Pour souligner la qualité de l'œuvre, on a employé l'expression decus ecclesiae, qui se trouve dans deux inscriptions d'Alcuin pour Saint-Hilaire-le-Grand de Poitiers et pour Saint-Denis, dans trois épitaphes, de 1037 à Liège, 1126 à la cathédrale de Toul, 1283 à la cathédrale de Beauvais 11', ainsi qu'à deux reprises chez l'abbé Suger pour les portes de Saint-Denis peu avant le milieu du XII ${ }^{\mathbf{e}}$ s. ${ }^{113}$. L'expression Christe pie se

108. Art mosan aux $x I^{p}$ el $x I^{p}$ s.. par Suzanne Collon-Gevafrt. Jean Lejecxe et Jacques Strinow. Bruxelles. 1961, p. 74-76.

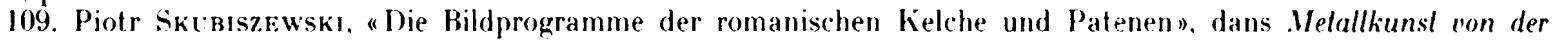

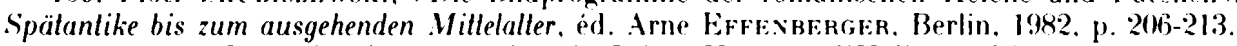

110. P.L.. 117. c. 1203 (attribue dans la P.L. a Haymon d'Halberstadt).

111. Die Inschriften der Stadl Osnabrück, ed. Sabine Wenkivg, Wiesbaden. 1988 (Die deutschen Inschriften, 26). p. $16-18, n^{\circ} 9$.

112. Vita Reginardi par Rénier de Liegge, M.G.ll., Ss, 20, èd. (i. H. Pertz. Hanovre, 1868, p. 578: - Gallia christiana. 13 , c. 997 et $\mathrm{IX}$, c. $747-748$.

113. (Euures completes de Suger, éd. A. Lecoy de La Marche. Paris, 1867 (Sociéte de l'histoire de France). p. InX. 
rencontre dans une épitaphe de Saint-Bénigne de Dijon du $\mathrm{XII}^{\mathrm{e}}{ }^{\mathrm{s}}{ }^{114}$. Marie est identifiée par un SANCTA MARIA, et le donateur lui adresse la salutation angélique telle que la liturgie l'a fixée à l'époque romane, c'est-à-dire avec un Maria qui n'est pas dans Luc, ave Maria GRatia Plena. La scène renvoie en même temps au mystère de l'Incarnation qu'annonce Isaïe et que, dans le tétramorphe, symbolise Matthieu.

De même que la composition s'ordonnait, verticalement, de façon principale à partir de trois quaternités - fleuves, vertus, évangélistes -, de mème les trois grandes scènes, après la scène de donation, sont relatives au baptême et en étroite corrélation. Dans la première de ces trois scènes, Moïse (MOYSES) avec son bâton sépare les eaux de la mer Rouge à travers lesquelles les Hébreux échappent aux Egyptiens leurs anciens maîtres. Sur l'arcade trilobée qui couvre la scène on lit:

PER MARE PER MOYSEN FUGIT EGIPTUM GENLS EORLM

PER CHRISTUM LAVACRO FUGIMUS TENEBRAS VICIORUM.

"Par la mer, par Moyse, leur race fuit l'Égypte,

Par le Christ, dans le baptême, nous fuyons les ténèbres des vices».

Le texte est remarquablement ordonné, chaque vers occupant la moitié de l'arcade trilobée. Le PER MOYSEN se trouve exactement au-dessus de Moïse, et c'est peut-être la raison pour laquelle on a commencé le vers par un PER MARE qui ajoute un pied supplémentaire à l'hexamètre. Le fugit et le fugimus sont écrits de façon exactement symétrique. Les vers se terminent par des rimes riches (versus caudali). La signification typologique du passage de la mer Rouge est déjà annoncée par les prophètes, Isaie XLIII, 16-17 ou LI, 10, Jérémie XXIII, 7, ce dernier associé, sur la cuve, à cette scène. Paul affirme expressément : «Nos pères étaient tous dans la nuée, tous ils passèrent à travers la mer, et tous furent baptisés en Moise dans la nuée et dans la mer" (1 Corinthiens X, 1-2). Jean Daniélou a souligné que "la typologie du baptême ... rentre dans l'enseignement catéchétique officiel donné par l'Église et par le Magistère». On expliquait aux nouveaux baptisés les figures du baptême, et "ces types sont toujours à peu près les mèmes, ce qui montre bien que nous sommes en face d'une tradition commune. Parmi ces figures la sortie d'Égypte et la traversée de la mer Rouge tiennent une place privilégiée "115. Le thème se rencontre pour la première fois dans le De baptismo de Tertullien : "Quelle figure pourrait ètre plus manifeste pour le sacrement du baptême? Les nations sont libérées du siècle par l'eau" "16. Zénon de Vérone souligne que "les juifs sont parvenus au désert par la mer, tandis que nous, nous arrivons au paradis par le baptême, l'eau ayant détruit tous les péchés" "117. Après Tertullien, l'auteur le plus important pour la catéchèse baptismale est Ambroise de Milan : "Alors déjà se trouve figuré d'avance le saint baptême dans ce passage des Hébreux où l'Égyptien périt, tandis que l'Hébreu échappa. Quel autre enseignement recevons-nous chaque jour par ce mystère, sinon que la faute est engloutie et l'erreur abolie, tandis que la piété et l'innocence traversent intactes?"118. Les Pères de l'Église d'Orient ont le même commentaire ${ }^{119}$. Augustin est revenu à de nombreuses reprises sur ce passage de la mer Rouge : "la mer Rouge signifie le baptême; le conducteur à travers la mer Rouge, Moïse, signifie le Christ; le peuple qui passe signifie les fidèles; la mort des Égyptiens signifie l'abolition

114. Gabriel Demay, Église et abbaye de Saint-Bénigne de Dijon, Paris/Dijon, 1882, p. 107.

115. Jean Daní́lou, "Traversée de la mer Rouge et baptême aux premiers siècles", Recherches de science religieuse. XXXIII, 1946, p. 402, 405.

116. P.L., 1, c. 1209.

117. Ibid., 11, c. 519.

118. Ambroisf de Mulan, Des sacrements, Des mysteres, op. cit. n. 95, p. 162-163: voir aussi p. 67, 71.

119. J. Danitioc, op. cit. n. 115 , p. 412-415, 417, 420, 422, 426: Origène. Grégoire de Nysse, Cyrille d'Alexandrie, Théodoret de Cyr. Basile. Jean Chrysostome. 
des péchés " ${ }^{120}$. Sedulius ${ }^{121}$, Prosper d'Aquitaine, Quodvultdeus ${ }^{122}$, Haymon d'Auxerre ${ }^{123}$, Grégoire de Tours ${ }^{124}$, Grégoire le Grand ${ }^{125}$, Isidore de Séville ${ }^{126}$, que reprend littéralement Bède ${ }^{127}$, traitent aussi du passage de la mer Rouge comme figure du baptème et voient, comme Augustin, dans la mort des Égyptiens, le signe que les péchés sont enlevés par le baptême. Leidrad de Lyon, Théodulphe d'Orléans, Raban Maur pour l'époque carolingienne ${ }^{128}$, saint Bruno, Yves de Chartres, Rupert de Deutz, Hildebert de Lavardin, Pierre Lombard pour le xil ${ }^{\mathrm{e}}$ s., reprennent le même thème ${ }^{129}$. Hildebert explique ainsi en peu de mots "ce que signifie la sortie d'Israël de l'Égypte : l'Égypte est le monde, le Pharaon Satan, les Israélites nous, le baptême la mer Rouge. Le roi est submergé par les eaux et le royaume de Satan périt dans le baptême " ${ }^{130}$. Jean Beleth note, en outre, que comme Moïse guidait les fils d'Israël, "le Christ précède les baptisés et les protège contre les incitations aux vices" 131 . L'abbé Suger pour les vitraux de l'abbaye de SaintDenis au milieu du xir ${ }^{e}$ s. ${ }^{132}$, Nicolas de Verdun, en 1181, dans le retable de Klosterneubourg, ont retenu le passage de la mer Rouge comme figure vétéro-testamentaire du baptême du Christ ${ }^{133}$.

Fait suite au passage de la mer Rouge le baptême du Christ dans le Jourdain, une scène qui s'impose dans tout programme iconographique développé sur des fonts baptismaux et que l'on trouve ainsi dans les célèbres fonts de Saint-Barthélemi de Liège de 1107/08 ${ }^{134}$, dans ceux de Saint-Germain de Tirlemont en $1149^{135}$ ou dans ceux de la cathédrale d'Osnabrück offerts au $\mathrm{XIII}^{\mathrm{e}}$ s. par Wilbernus. À Hildesheim, dont l'iconographie est très proche de celle de Liège, on a de gauche à droite Jean Baptiste qui met sa main droite sur la tête du Christ, le Christ plongé dans l'eau du Jourdain, à mi-corps, deux anges qui portent des voiles ${ }^{136}$; au-dessus du Christ est l'Esprit Saint sous la forme d'une colombe, et au sommet de l'arcade trilobée le buste du Père qui bénit de la main droite et tient de la gauche un phylactère sur lequel on lit : HIC EsT Filius mecs Dilectus, ce qui est une citation de Matthieu (III, 17) et de Luc (IX, 35). Au-dessus de la scène sont gravés deux hexamètres léonins riches :

120. P.L.. 35, c. 1723; voir aussi 36. c. $917: 37$, c. 1037. 1410-1411. 1420: 39. c. 1551, 1555. 1562. 1635.

121. Ibid., 19, c. 567 .

122. Ibid.. 51. c. 307, 389 (Prosper): c. 764-765 (Qvodvitutdeus).

123. Ibid., 70, c. 1059 (attribué dans la P.L. à Cassiodore).

124. Ibid., 71, c. 168 .

125. Ibid., 77 , c. 1162

126. Jbid., 83 , c. 296.

127. Ibid., 93, c. $370-371$

128. Ibid., 99, c. 855 (Leidrard); 105, c. 231-232 (Théodulphe): 108 , c. 66 (Raban Maur).

129. Ibid., 152, c. 1035-1036 (Brivo); 162 , c. 507 (Yves); 169 , c. 796 et 170, c. 162 (Rupert); 191 , c. 1618 (Pitraf LOMBARD)

130. "The "Biblical Epigrams" of Hildebert of Le Mans. A Critical Edition", par A. B. Scott, D. F. Bakfr et

A. G. Rigg, Mediaeval Sludies, XLVII. 1985, p. 282.

131. J. Bel.eth, Ralionale divinorum officiorum, P.L., 202, c. 113.

132. Louis GrodfCKI, Les vitraux de Saint-Denis. Elude sur le vilrail au $x u^{e}$ s.. I. Paris, 1973 (Corpus vilrearum Medii Aevi. France. Série Études, I). p. 96-97:

QLOD BAPTISMA BONIS HOC MILITIE PHARAONIS

FORMA FACIT SIMILIS CAUSAQLE DISSIMILIS.

133. Helmut Buschracsen, Der Verduner Altar: des Emailwerk des .Vikolaus von Verdun im Stift Klosterneuburg. Vienne, 1980, p. 36-37:

U.NDA RLBENS MUNDA BAPTISMI MISTICAT LNDA.

134. Art mosan aux $x^{\prime}$ el $X I^{\circ}$ siecles, op. cit. n. 108, p. 172-180:- Bruno RecdevaAch. Das Taufbecken des Reiner von Huy in Lültich, Wiesbaden, 1984.

135. Rhin-Meuse. Art el civilisation 800-1400, op. cil. n. 36, p. 70; - DinnoN, "Bronze et orfèvrerie du Moyen Àge". Annales archéologiques, XIV, 1859, p. 188, n. 5 .

136. Les anges ne sont pas cités dans les Évangiles pour cette scène. mais le sont dans l'épisode de la tentation au désert qui suit. Leur présence au baptème du Christ est inspirée de l'art bỹantin. Mème iconographie, mais avec un seul ange. dans l'émail mosan de 1150/60 conservé au Metropolitan Museum of Art de . New York (Neil Stratford, Catalogue of Medieval Enamels in the British .Museum. II. Northern Romanesque Enamels. Londres. 1993. p. 59. pl. 13). 
HIC BABTIZATUR CHRISTUS QUO SANCTIFICATUR NOBIS BABTISMA TRIBLENS IN FLAMINE CRISMA "Ici est baptisé le Christ, par qui est sanctifié pour nous le baptème, grâce à l'onction qu'il nous accorde dans l'Esprit".

La métrique a conduit à retenir le mot de flamen pour le Saint Esprit ${ }^{137}$. Le nom du Christ est donné en abrégé avec les lettres grecques, XPc, comme sur les fonts baptismaux d'Osnabrück. Le chrême intervient déjà dans le baptême du temps de Tertullien ${ }^{138}$. Pacien de Barcelone au Ive s. appelle le chrême "l'onguent du Saint Esprit" ${ }^{139}$, et Augustin écrit que le chrême est "le signe visible de la grâce qui fait de nous des rois et des prêtres, des membres du Christ par les vertus de l'Esprit" ${ }^{140}$. Dans la liturgie on utilisera le chrême d'une part en le mélangeant à l'eau baptismale ${ }^{141}$, de l'autre en signant le front du nouveau baptisé ${ }^{142}$.

Au baptême du Christ dans le Jourdain fait suite le passage du Jourdain par les Hébreux avec l'arche d'alliance, et leur entrée dans la Terre promise sous la conduite de Josué (Josué III, 7-17), une autre figure vétéro-testamentaire du baptème [fig. 3]. Au-dessus de la scène on lit :

AD PATRIAM JOSUE DUCE FLUMEN TRANSIT HEBRELS

DUCIMUR AD VITAM, TE DUCE FONTE DEUS

"Sous la conduite de Josué l'Hébreu traverse le fleuve pour arriver en son pays.

Par ta source, Dieu, nous sommes, sous ta conduite, dirigés vers la vie».

Il s'agit d'un distique élégiaque avec rimes riches en finales (versus caudali). Le parallèle est clair entre la Terre promise ici-bas (ad patriam), et le ciel (ad vilam), entre Josué (duce) et Dieu (le duce). Au te duce, Caesar d'Horace ${ }^{143}$, fait écho le duce te que Constantin applique au Christ dans l'inscription de l'arc triomphal de Saint-Pierre du Vatican ${ }^{144}$, qui est repris par l'abbé Didier à l'arc triomphal de l'abbatiale du Mont-Cassin ${ }^{145}$ et en d'autres inscriptions ${ }^{146}$. On trouve l'expression ad patriam chez Micon de Saint-Riquier au $\mathrm{IX}^{\mathrm{e}} \mathrm{s} .{ }^{147}$ et dans trois inscriptions des $\mathrm{XII}^{\mathrm{e}}$ et $\mathrm{XII}^{\mathrm{e}}$ s. en France ${ }^{148}$. Le premier nom de Josué était Osée, c'est-à-dire "salut». Moïse le changera en "Yehoshoua" ${ }^{149}$, que les Septante traduisent par Jésus, la Vulgate par Josué ${ }^{150}$. Dès les pre-

137. Exemples dès le haut Moven Àge, cf. Thesaurus linguae latinae, III, Leipzig. 1906/12, c. 1028; - Albert BI.AISF, Dictionnaire latin-français des auteurs chréliens, Paris, 1954, p. 148.

138. Tertulliten, Liber de baplismo, P.L., 1, c. 1206-1207.

139. Pacien de Barchione, Sermo de baptismo, P.L., 13, c. 1093.

140. Acgustin, De Trinitale, XV, 26, P.L., 42, c. 1093 ; mème affirmation dans la lettre de Jean Diacre à Senarius, P.L., 59, c. 403.

141. Le pontifical romano-germanique du dixième siècle, éd. Cyrille Vogre et Reinhard E.z. II, Cité du Vatican, 1963, p. 101-104; - Jean Beleth, Rationale divinorum officiorum, P.L., 202, c. 113.

142. Sicard de Crémone, Mitrale, P.L., 213, c. 334.

143. Carmina, I, 2.

144. Inscriptiones christianae urbis Romae septimo saeculo antiquiores. II, pars prima, éd. J.-B. De Rossı, Rome. 1888, p. 20 ; - Richard Krautheimer, Spencer Corbett et Alfred K. Frazer. Corpus basilicarum christianarum Romae. Le basiliche paleocristiane di Roma (IV-IX Sec.), V, Cité du Vatican, 1980 (Monumenti di Antichitá cristiana pubblicati dal Pontificio Istituto di Archeologia cristiana. II. Serie), p. 177.

145. Chronica monasterii Casinensis, éd. W. Wattenbach, M.G.H., SS., VII, 1. III (Auclore Leone), § 28. Hanovre, 1846 , p. 718.

146. Gallia christiana, VIII, épitaphe d'Yves de Chartres, c. 1132; - C.I.F.M. 15. La ville de Vienne en Dauphiné, ed. R. Favreau, J. Michaud et B. Mora, Paris, 1990, $n^{\prime 2} 77$. p. 78, épitaphe de Bernon. $2^{e}$ moitié xire s. On trouve aussi me duce dans les inscriptions de Suger à Saint-Denis (Euvres, èd. Lfcoy dF La MarchF, p. 190). Sedulius emploie aussi le te duce dans son Carmen paschale, I. I, vers 85 (P.L., 19, c. 561). Cf. Matthieu II, $6:$ Ex te enim exiet dux, qui regat populum.

147. Poetae latini aevi carolioni, III, ed. Ludwig Travbe, Berlin, 1896 (.M.(i.ll.. Poetarum latinorum medii aevi. III). p. 313.

148. Epitaphe de Letard, abbé du Bec-Hellouin. en 1149 (L. Des.rst.f, Chronique de Robert de Torigni .... Rouen. I. 1872, p. 249); linteau du tympan de l'abbatiale de Déols, xII" s. (J. Herfre, "L'abbatiale Notre-I)ame de Déols", Bulletin monumental. LXXXVI. 1927, p. 48); tombeau (disparu) de Philippe de France à Asnières-sur-()ise, XIII s. (Ph. Lal'rr. "L'abbaye de Royaumont", ibid.. LXXII, 1908, p. 255).

149. Nombres XIII, 17 (pour la T.O.B. 16).

150. Jean Janiriou, Sacramentum futuri. Études sur les origines de la typologie biblique, Paris, 1950) (Études de théologie historique), p. 201-256, le cycle de Josué (notamment le nom de Josué). 
miers auteurs chrétiens on a vu en Josué une figure de Jésus puisqu'il avait le même nom (Tertullien) ${ }^{151}$, et dans le franchissement du Jourdain sous sa conduite une figure du baptême : "Le juste franchit la mer Rouge comme s'il marchait à sec ... C'est ainsi qu'il en est au Jourdain. L'Arche d'alliance conduisait le peuple de Dieu... À toi, chrétien, qui, par le mystère du baptême, as franchi le cours du Jourdain la parole de Dieu te promet des biens beaucoup plus grands et beaucoup plus élevés" (Origène) ${ }^{152}$. Après avoir parlé du baptême du Christ dans le Jourdain, saint Chromatius, évêque d'Aquilée, écrit : "La gràce du baptême nous a été montrée à l'avance de façon mystique lorsque le peuple fut conduit, par le fleuve Jourdain, dans la Terre promise, à la suite du Seigneur, ainsi maintenant par les mêmes eaux du Jourdain, le premier chemin de la voie des cieux a été ouvert, par lequel nous sommes conduits à la bienheureuse Terre promise, c'est-àdire à la promesse du royaume des cieux. Pour eux Jésus fils de Nave fut le guide (dux) dans le Jourdain. Pour nous le Seigneur Jésus Christ est, par le baptême, le guide du salut éternel " 153 . Ambroise, Jérôme, Augustin voient de mème en Josué "le type du Seigneur, non seulement en gestes, mais même en nom" ${ }^{154}$, celui qui n'a pas douté et que Dieu a choisi pour conduire le peuple en la Terre promise ${ }^{155}$. Quodvultdeus, Isidore de Séville, Bède le Vénérable, Raban Maur ne disent pas autre chose ${ }^{156}$. Éribert de Reggio constate que des fils d'Israël qui ont été libérés de la servitude d'Égypte, seuls sont entrés en la Terre promise Caleb et Josué, "qui désignent la tête et le corps, c'est-à-dire le Christ et l'Église, qui seuls entreront dans cette terre des vivants" ${ }^{157}$. Au $\mathrm{XII}^{\mathrm{e}}$ s. aussi saint Bruno, Anselme de Laon, Rupert de Deutz, Jean Beleth reprennent le passage du Jourdain par Josué comme une figure du baptême, et l'arrivée en la Terre promise comme le passage de la terre stérile du péché à la terre irriguée et fertile du chrétien libéré du péché par le Christ et la grâce du baptême ${ }^{158}$. Mais la liturgie n'a rien retenu du livre de Josué, et l'iconographie qui est propre à Josué n'est pas très développée.

On trouve ainsi sur la cuve des fonts baptismaux d'Hildesheim à la fois une théologie sacramentelle du baptême : mort du péché, naissance (renatus) d'un homme nouveau qui peut s'appliquer à une vie droite (vertus cardinales) à l'image et avec l'aide du Christ, source de vie (fleuves du paradis, Évangiles), et une présentation de plusieurs figures du baptême : passage de la mer Rouge, baptème du Christ, passage du Jourdain - sous la conduite de Josué. Sur le couvercle sont présentés les quatre différents genres de baptême [fig. 4], dont les quatre vers inscrits à la base du couvercle donnent le sens :

\author{
MUNDAT UT INMUNDA SACRI BABTISMATIS LNDA \\ "L'eau du saint baptème purifie ce qui est comme impur" \\ SIC JUSTE FLSUS SANGLIS LAVACHRI TENET USLS \\ "Ainsi à juste titre le sang versé tient lieu de baptême"
}

151. P.L., 2. c. 343.

152. Origènf. Homélies sur Josué, éd. Annie Jac'bert, Paris, 1960 (Sources chrétiennes. 71). p. 147-149. Cf. aussi Grígoirf de .irsse. De baptismo: "Imite Jésus. fils de Nave ... Laisse-là le désert. c'est-à-dire le péché. Traverse le Jourdain, hàte-toi vers la vie (l'inscription d'Hildesheim dit : ad vilam) selon le Christ "(Jean Davirisot, Bible el liturgie. Paris. 1951 (Lex orandi, 11). p. 141).

153. P.L.. 20, c. 330 .

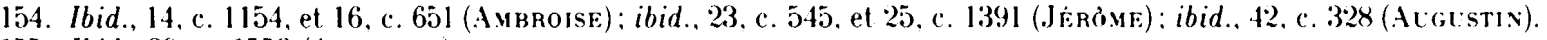

155. Ibid., 39. c. 1553 (Avglestix).

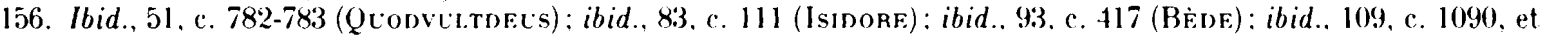
111, c. 54 et 321 (RaBan MaLR).

157. Ibid., 79, c. 630 (attribué dans la P.L. à (irégoire le Grand).

158. Ibid., 152, c. 815 (Brevo) : ibid., 113, c. 508 (Gilose ordinaire attribuèe à tort a 11 . Strabon. mais ceuvre d Anselme

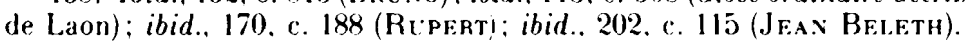




\section{POST LAVAT ATTRACTA LACRIMIS CONFESSIO FACTA \\ "La confession faite dans les larmes lave ce qui a été avoué" \\ CRIMINE FEDATIS LAVACHRUM FIT OPUS PIETATIS \\ "L'œuvre de piété devient baptême pour ceux qui sont souillés par le péché»}

c'est-à-dire le baptême par l'eau, par le sang, par la pénitence, par les œuvres de miséricorde. On notera l'emploi de l'hexamètre léonin riche pour chaque genre de baptême, et l'insistance sur le baptême qui lave de tous les péchés : mundat, unda, lavachrum, laval.

La première scène représente la floraison de la verge d'Aaron. Lorsque le peuple hébreu se mit à contester l'autorité de Moïse et d'Aaron, le Seigneur demanda à Moïse de se faire remettre un bâton par chacun des chefs des douze tribus; leurs noms seront inscrits sur les bâtons, et pour la tribu de Lévi on mettra le nom d'Aaron; les bâtons seront déposés dans "la tente de la rencontre", et le Seigneur fera fleurir le bâton de l'homme qu'il choisira. Au matin Moïse entra dans la tente et "vit que le bâton d'Aaron, de la maison de Lévi, avait bourgeonné : il avait fait surgir un bourgeon, éclore une fleur et mûrir des amandes" ${ }^{159}$. Moïse et Aaron sont identifiés par leurs noms (MOYSEs, Aaron), et Moïse tient un phylactère sur lequel on lit: PROPHETAM SUSCITABIT DE FRATRIBUS vESTRIS, "Il vous suscitera un prophète parmi vos frères", ce qui est une citation du Deutéronome telle que la reproduisent les Actes des apôtres ${ }^{160}$. Ce texte du Deutéronome est repris, plus ou moins littéralement, dans un certain nombre d'œuvres : mosaïques de Monreale et de Palerme, peintures murales du baptistère de Parme, de San Nicola in Carcere à Rome, de Sant'Angelo in Formis, de Windish-Matrei, ambon de San Leonardo in Arcetri à Florence, sculptures de Notre-Dame-la-Grande à Poitiers, vitrail de Saint-Denis, psautier de Shaftesburg Abbey à Londres ou Bible de Saint-Bertin à Paris ${ }^{161}$.

Au-dessus de la scène le roi Salomon (Salomon rex) tient un texte tiré de l'Écclésiastique : Flores mei fructus hoNoris et hoNestatis, "mes fleurs sont des fruits d'honneur et d'honnêteté» 162. Sur l'arcade trilobée qui enserre la scène est gravé un hexamètre léonin riche, où la recherche de style est évidente (virga, viget, vigente) :

VIRGA VIGET FLORE PARIT ALMA VIGENTE PLDORE

"La verge vigoureuse est en fleur, la mère enfante toujours vierge".

Les textes sont en relation évidente avec la verge fleurie d'Aaron. Le rapport est non moins évident avec le texte dans lequel, sur la cuve, le prophète Isaïe annonce la maternité de Marie, "un rameau (virga) sortira de la souche de Jessé». Saint Césaire a d'ailleurs fait, dans l'un de ses sermons, le rapprochement entre la verge d'Aaron et la verge de Jessé ${ }^{163}$. Le verset qui suit la citation de l'Écclésiastique dit : "Moi, je suis la mère du bel amour, de la crainte, de la science et de la sainte espérance, en moi est toute grâce de voie et de vérité", et quelques versets plus loin sont évoqués les fleuves du paradis. Le commentaire de la scène, "la mère enfante toujours vierge" renvoie de même à la Vierge à l'Enfant représentée sur la cuve. S'il y a un rapport voulu entre cuve et couvercle, on peut se demander comment dans l'épisode du bâton fleuri d'Aaron on a vu une figure du baptême par l'eau, comme le dit expressément le vers inscrit, sous la scène, au bord du couvercle. D'abord saint Ambroise, un témoin capital pour l'histoire du baptême, explique comment la floraison du bâton d'Aaron est une figure du baptême : "Il y avait, dans la seconde tente, le bàton d'Aaron, qui s'était desséché puis avait refleuri ... À quoi cela tend-il? À vous faire

159. Nombres XVII. 9-12.

160. Deutéronome XVIII, 15 : Prophelam de gente lua et de fratribus tuis, sicut me suscitabil tibi Dominus Deus tuus. Actes VII. 37 : Moyses dixit : quoniam prophetam suscilabit vobis Dominus Deus vester de fratribus nestris. Voir aussi Deut. XVIII, 18.

161. Françoise Gay, Les prophètes. Épigraphie. I. Poitiers, 1980 (these de 3 " cycle. dactyl.), p. 99.

162. Écclésiastique XXIV, 23 (Vulgate; pour la Bible de Jérusalem et la T.O.B. XXIV. 17).

163. P.L.. 39. c. 1807, de virga Aaron (dans les couvres d'Augustin). 
comprendre ce qu'est cette seconde tente, dans laquelle le prêtre vous a introduits, celle dans laquelle le grand-prêtre a coutume d'entrer une fois par an, c'est-à-dire le baptistère où le bâton d'Aaron a fleuri. Il était desséché, puis il a refleuri. Toi aussi, tu étais desséché et tu as commencé à refleurir dans l'eau courante de la fontaine. Tu étais desséché par les péchés, tu étais desséché par les erreurs et les fautes, mais tu as déjà commencé à porter du fruit, planté que tu es près du cours des eaux" ${ }^{164}$. On aura noté qu'Ambroise évoque les "fruits" que porte le chrétien régénéré par le baptême. Peut-être aussi faut-il penser à l'épisode qui suit la floraison du bâton d'Aaron, lorsque le peuple a soif et récrimine contre Moïse. Celui-ci et Aaron se rendent à "la tente de la rencontre", Moïse y prend "le bâton qui se trouvait devant le Seigneur" - ce pourrait ètre le bâton d'Aaron - et en frappe le rocher d'où l'eau jaillit en abondance ${ }^{16.5}$. C'est aussi une figure du baptême ${ }^{166}$. Mais on peut encore évoquer le rapprochement qui est fait par saint Léon le Grand, dans deux sermons sur la Nativité, entre l'Incarnation et le baptême, puisqu'aussi bien c'est un rapprochement que peut suggérer la présence de Matthieu sur la cuve. Dans le sermon 25 Léon écrit : "Il a placé dans la fontaine baptismale l'origine qu'il a prise dans le sein de la Vierge. Il a donné à l'eau ce qu'il a donné à la mère. La même vertu du Très Haut et l'ombre du Saint Esprit ${ }^{167}$ qui ont fait que Marie a enfanté le Sauveur, font que l'eau régénère le croyant "168. Verge de Jessé, verge d'Aaron, maternité de Marie se conjuguent finalement pour signifier le baptême par l'eau que citent tous les auteurs. Mais, comme le dit Hugues de Saint-Victor, s'il n'y a qu'un seul baptême, celui par l'eau, il y a d'autres genres de baptême qui peuvent le suppléer ${ }^{169}$. Le deuxième genre de baptême est le baptême par le sang du martyre. La deuxième scène, le massacre des saints innocents sur l'ordre d'Hérode (HERODEs), est commentée par le vers gravé sur l'arcade trilobée :

QUOS DOLOR OSTENTAT CRUOR A CRUDELE CRUENTAT

"La douleur les montre, ceux que le sang répandu par le (roi) cruel ensanglante».

Comme dans la scène précédente, on a un hexamètre léonin riche et une recherche d'effet par la répétition (cruor, crudele, cruental). Ce massacre est annoncé par le prophète Jérémie (hieremias PROPHETA) qui tient un phylactère sur lequel on lit, en abrégé pour la fin du texte:

vox in rama aldita, ploratus et ululatus rachel plorans filios suos

"Une voix dans Rama s'est fait entendre, des pleurs et des cris de lamentation,

Rachel qui pleure ses enfants".

En fait ce n'est pas le texte même de Jérémie (XXXI, 15) qui est reproduit, mais la citation qu'en fait l'évangéliste Matthieu (II, I8), lorsque, précisément, il rapporte le massacre ordonné par Hérode, des enfants de Bethléem, comme, dans la scène précédente, le Deutéronome était cité d'après les Actes des apôtres. Rachel, mère des Israélites du Nord, pleure sur ses enfants exilés, et Rama, que mentionne Matthieu ${ }^{170}$, est, d'après le même Jérémie (XL, 1), le lieu de rassemblement des déportés partant en exil. Le tombeau de Rachel est toujours vénéré près de Bethléem, à l'endroit où se trouvait le champ de Rama. Quodvultdeus, Bède le Vénérable, Raban Maur ${ }^{171}$

164. Ambroise df. Milan, Des sacrements. Des mysteres, op. cit. n. 95. p. 102-103.

165. Nombres XX, 2-11.

166. Par ex. pour Isidore de Sirvil.e. P.L.. 8.3, c. 299.

167. Cf. Luc I. 35.

168. Walter M. Bédard. The Symbolism of the Baptismal Font in Early Christian Thought. Washington. D.C... 1951 (The Catholic Lniversity of America Studies in Sacred Theology. Second Series. 45). p. 35. Le texte de Leon le (irand peut également évoquer la création. l'eau qui couvre la terre et sur laquelle plane l'Esprit de Dieu, figure retenue aussi pour le baptème : SPIRITLS DEI FEREBATLR SLPER AQLAS (Genèse I. 2).

169. P.L., 177. c. 804. Attribution incertaine (voir F. Varnfet. Dictionnaire de theologie catholique. VII-1, Paris, 192:2, c. 240-308).

170. Jérémie dit : Vox in excelso. Le mot de Rama est. daprès certains, le nom commun de hauteur (par ex. Maxime de

Turin. P.L.. 57. c. 920 ou Raban Maur. ibid.. 107. (. 76:3). Matthieu le prend comme un nom de lieu.

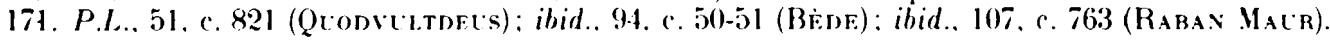


font le rapprochement entre la douleur de Rachel et le massacre des Innocents, et ils savent que le tombeau de Rachel existe toujours près de Bethléem ${ }^{172}$. Ce rapprochement se trouve aussi dans la liturgie de la fête des Saints-Innocents, aussi bien dans le messe du jour que dans l'office des Nocturnes ${ }^{173}$.

Pour Hilaire, Augustin, Sévérien de Gabala, Bède, Raban Maur ${ }^{174}$, la mort a valu aux enfants innocents l'éternité bienheureuse. Bède souligne qu'"en la mort des innocents est désignée la mort précieuse de tous les martyrs". Pour Hilaire, Maxime de Turin ${ }^{175}$, Bède, Rachel est la figure de l'Église. Sévérien de Gabala dit que les saints Innocents ont été baptisés dans les larmes de leur mère, et dans leur propre sang. Augustin part du massacre des Innocents pour réfuter ceux qui estiment qu'on ne doit pas baptiser les jeunes enfants ${ }^{176}$.

Ici la scène du massacre des Innocents illustre la possibilité du baptême par le sang dans le martyre, comme l'indique le vers placé sous la scène. Pour Tertullien, qui écrit alors que les grandes persécutions ne sont pas terminées, il y a deux baptèmes, par l'eau, et par le sang ${ }^{177}$, et les deux ont leur source dans la blessure du côté du crucifié, d'où ont coulé du sang et de l'eau. Fulgence de Ruspe au début $d u v^{e}$ s. ne reconnaît, lui aussi, que le baptisma fluminis et le baptisma sanguinis ${ }^{178}$. Leidrad, évêque de Lyon $(\dagger 813)$, ne retient également que deux genres de baptêrne, par l'eau et par le sang ${ }^{179}$. Lorsque les auteurs retiennent plus de deux genres de baptême, le baptême par le sang est toujours cité.

Le massacre des Innocents et le baptème par le sang doivent être mis en rapport avec le passage de la mer Rouge, deuxième scène figurée sur la cuve. Commentant le passage de la mer Rouge comme figure du baptême, Augustin s'interroge : "Pourquoi rouge?" et répond : parce qu'elle est "consacrée par le sang du Seigneur" ${ }^{180}$. Pour Cassiodore la mer Rouge renvoie à la blessure de la lance sur la croix d'où sortit l'eau du baptème avec le sang ${ }^{181}$. Bède le Vénérable, Hildefonse de Tolède, Leidrad, Théodulphe d'Orléans, saint Bruno, Yves de Chartres, Rupert de Deutz, Pierre Lombard ${ }^{182}$ font le même rapprochement entre mer Rouge et sang du Christ, avec les termes mêmes d'Augustin, baptismus Christi sanguine consecralus. Le baptème du sang est ainsi lié étroitement à la Passion du Christ.

Dans le troisième tableau Jésus est à table chez Simon le pharisien. "Survient une femme de la ville qui était pécheresse ... Se plaçant, tout en pleurs, aux pieds de Jésus, elle se mit à baigner ses pieds de larmes; elle les essuyait avec ses cheveux" (Luc VII, 36-38). L'auteur du programme a reproduit sur le phylactère du pharisien l'interrogation que celui-ci formula "en lui-même»: HIC, sı ESSET PROPHETA, SCIRET UTIQUE QUALIS ET QLE MULIER qui TANGIT EUM, «Si cet homme était un prophète, il saurait bien quelle est cette femme qui le touche»(Luc VII, 39). Jésus fait observer à

172. Bède précise : Rachel juxta Bethleem sepulla est, sicut titulus monumenti ejus manens usque hodie testalur, ad occidentem civitatis, ultra viam quae ducil Hebron. Raban Maur copie littéralement Bède.

173. Corpus anliphonalium officii, ed. R.-J. Hesbert, III, Rome, 1968 (Rerum ecclesiasticarum documenta. Series major. Fontes IX), p. 549, n 5508, et IV, Rome, 1970 (ibid., Fontes X), p. 471 , ns 7919 et 7920.

174. P.L., 9, c. 923 (HItalRe); ibid., 39, c. 1664, 1668, 2150 (Augustin, attribution douteuse); ibid., 52, c. 606 (SÉveRien de Gabala dans les ouvres de Pierre Chrysologue); ibid., 94, c. 50,53 (Bède); ibid., 107, c. 763 (Raban). Voir aussi une hymne de Bède, dans Analecta hymnica medii aevi, éd. Cl. Bl.t.me et G. M. Dreves, 50. Hymnographi latini, Leipzig, 1907, p. 102-103.

175. P.L., 57, c. 920 (attribution douteuse).

176. Sermo 373, de Epiphania, P.L., 39, c. 1664 (Avqusrin, allribution douteuse) : ils n'ont pas l'âge de croire dans le Christ qui a souffert la Passion, mais ils sont la chair en laquelle on croit au Christ qui a souffert la Passion.

177. P.L., 1, c. 1211 (Liber de baptismo) : secundum lavacrum ... sanguinis.

178. John J. Gavigan, "Fulgentius of Rupe on Baptism», Traditio, V. 1947, p. 317.

179. P.L., 99, c. 861 (Liber de sacramento baptismi).

180. Ibid., 37, c. 1037. Cf. aussi ibid., c. 1411, c. 1420 : sacramento tanquam rubri maris, baptismo scilicet Christi sanguine consecralo ...; ibid., 39, c. 1562 : mare rubrum, baptisma scilicel Christi sanguine consecratum.

181. Ibid., 70, c. 588 .

182. Ibid., 93, c. 370 (BÈDE); ibid., 96, c. 149 (HILDEFONSE ; peut-ètre plutòt ceuvre de Justinien de Valence); ibid., 99, c. 862 (Leidrad de Lyon); ibid., 105, c. 232 (Théoncl.phe); ibid., 152, c. 1035 (Bruno); ibid., 162, c. 507 (Yvrs dF Chartres); ibid., 169. c. 796 (Rupert): ibid., 191. c. 1618 (Pifrre Lombard, copie Bitdf). 
Simon que la pécheresse lui a baigné les pieds de ses larmes, les a essuyés avec ses cheveux, a couvert ses pieds de baisers, a répandu du parfum sur ses pieds, et lui déclare que "ses péchés si nombreux ont été pardonnés parce qu'elle a montré beaucoup d'amour". Sur le phylactère tenu par Jésus on lit: RemitTuntur ei Peccata multa, "ses nombreux péchés lui sont remis" (Luc VII, 47). L'inscription gravée sur l'arcade trilobée rappelle que les larmes permettent la rédemption :

\section{SPES REFICIT PECTUS LACRIMIS A FLENTE REFECTUS}

"Restauré par les larmes le cœur de celui qui pleure retrouve l'espérance»,

soit à nouveau un hexamètre léonin riche, avec recherche d'effet par des répétitions (reficit, refectus) ${ }^{183}$. Au-dessus de la scène le roi David (David REX) tient une banderole avec un verset de psaume 184 : CIBABIS NOS PANE LACRIMARCM ET POTLM DABIS NOBIS IN LACRIMIS IN MENSURA, "tu nous as nourris du pain de larmes et abreuvé de larmes à pleine mesure", citation qui permet de retrouver à deux reprises les larmes, qu'évoque aussi le vers placé sous la scène au bord du couvercle.

Il s'agit bien évidemment du baptême de pénitence. Le plus grand nombre des auteurs du moyen âge ont retenu trois genres de baptême, comme le dit une formule attribuée à Hugues de SaintVictor : Triplex est baptismus, fluminis, flaminis et sanguinis. Fluminis in aqua, flaminis in poenilentia, sanguinis in martyrio ${ }^{185}$. Un des premiers à parler de ces tria genera baptismi est Isidore de Séville, dans le De ecclesiasticis officiis, au chapitre 25 consacré au baptême : "Le troisième genre est le baptême des larmes (baptisma lacrymarum), qui se réalise avec plus de peine, comme celui qui chaque nuit arrose sa couche de ses larmes (Ps. VI, 7), qui imite la conversion de Manassé (2e livre des Chroniques XXXIII, 12-13), et l'humilité des habitants de Ninive (Jonas III, 5-10)...» "186. Hildefonse de Tolède cite comme troisième genre de baptême, "l'inondation des larmes (alluvium lacrymarum) qui a lieu quand on fait pénitence pour ses péchés, qui s'obtient avec peine mais est certain grâce à la grande miséricorde du Rédempteur. Ainsi de Marie qui, pécheresse en la cité, s'assied aux pieds du Christ ... et les lave par ses larmes " ${ }^{187}$. Alcuin parle du "baptême des larmes", Raban Maur "de la confession et de la pénitence avec les larmes", le pseudo-Hugues de Saint-Victor de la "vraie contrition du cœur", Martin de León, qui copie Isidore, du "baptême des larmes", Alain de Lille de "l'Esprit et du feu" (flamen) 188. Raban Maur, comme Hildefonse, évoque les larmes de la femme pécheresse ${ }^{189}$. Gratien admet que "l'espérance de la vie éternelle est obtenue non seulement par la grâce du baptème, mais encore par le remède de la pénitence ${ }^{190}$. Thomas d'Aquin, lui aussi, dans sa Somme théologique parlera de trois genres de baptème, aquae, sanguinis el flaminis ${ }^{191}$. On notera l'importance du mot "larmes" à côté de celui de "pénitence».

183. Il semble que la recherche de la rime riche a entrainé la forme refeclus, là où le neutre peclus aurait appelé refectum. Mais ces vers sont très laborieux et on pourrait trouver un certain sens avec refectus au masculin.

184. Psaume LXXX (LXXIX), 6.

185. P.L., 177, c. 804 (attribution douteuse). Sur la cuve baptismale de l'église de la Nativité à Bérulle, au xv" s., on peut lire : FLUMINIS, FLAMINIS, SA.NGUINIS (cf. QUESVERS et H. STEI.N. Inscriplions de l'ancien diocèse de

Sens .... II, Paris, 1900, p. 52-53). Voir aussi un ancien rituel de Limoges citant les tres baptismi species, ... fluminis.

... flaminis, ... sanguinis (De antiquis Ecclesiae ritibus libri qualuor, par dom E. MartÉ.ve, I, Rouen, 1700), p. 204).

186. P.L.. 83, c. $820-821$.

187. Ibid., 96, c. 160-161 (Liber de cognitione baptismi; peut-ètre plutòt œuvre de Justivien dE VALFNCE).

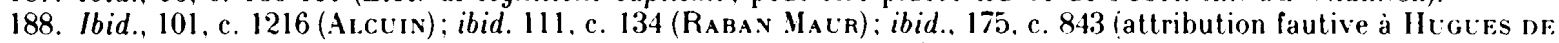
Saint-Victor): ibid., 208, c. 273 (Martin de León): ibid., 210, c. 348 (Alain de Lille.).

189. Ibid., 111, c. 134 (per confessionem el per paenitentiam veram cum lacrymarum compunctione) et c. 135 (de muliere peccalrice quae pedes ejus lacrymis rigavit).

190. Corpus juris canonici, éd. E. L. Richter et E. Friednerg, Pars prior. Decretum magistri Graliani, Leipzig. 1922. c. 1170 .

191. Summae thelogicae pars terlia, quaestio 66, de baptismo. article 11. 
Il n'y a pas de nom donné, dans l'Évangile, à la pécheresse pardonnée, mais à partir de Grégoire le Grand tous les auteurs chrétiens de l'Église d'Occident ont, au moyen âge, identifié la pécheresse à Marie-Madeleine en qui ils ont vu aussi Marie, sœur de Marthe, ou Marie, sœur de Lazare ${ }^{192}$. Or Marie-Madeleine était particulièrement vénérée à Hildesheim : en 1062, l'évèque Hézilo avait déposé dans le maitre-autel de sa cathédrale des reliques de Marie-Madeleine, el d'aulres reliques de la sainte furent aussi placées dans l'autel Saint-Martin de la cathédrale entre 1181 et 1190 ; vers 1225, un chanoine de Saint-Maurice d'Hildesheim fondera l'ordre des pénitentes de sainte MarieMadeleine ${ }^{193}$.

Deux références bibliques s'imposaient pour ce baptême de pénitence. Pierre - qui après son reniement s'est repenti et "a pleuré amèrement" (Matthieu XXVI, 34 ; Luc XXII, 62) - annonce dans ses premiers discours qu'il faut "faire pénitence (poenitentiam agile, poenitemini) et se convertir afin que ses péchés soient pardonnés" (Actes II, 37 et III, 19). Surtout Jean Baptiste, avant de baptiser Jésus, proclame dans le désert de Judée : "Faites pénitence (poenitentiam agite), car le royaume des cieux est proche" (Matthieu III, 1-2). Tertullien déjà, dans son Liber de baptismo, parlait du "baptême de pénitence" de Jean ${ }^{194}$, et Jean Cassien dans ses Collationes rappelle le discours de Pierre et le baptême de Jean ${ }^{195}$, Raban Maur renvoie aussi à l'invite de Jean Baptiste (Matthieu III, 2) reprise par Jésus (Matthieu IV, 17) ${ }^{196}$. On peut considérer qu'il y a là encore un rapprochement voulu entre la scène du baptême de Jésus par Jean sur la cuve, et le baptême de pénitence du couvercle. Ce sont d'ailleurs les deux seules scènes où apparaît Jésus, en dehors de la scène de donation. Il y a aussi sans doute une invite au chrétien : «nul ne peut bien accéder au baptême du Christ en lequel tous les péchés sont enlevés, s'il ne fait pas pénitence pour sa vie passée" (Augustin) ${ }^{197}$.

Le dernier genre de baptême est le baptême par les đuvres de miséricorde. Au centre de la dernière scène du couvercle trône une femme couronnée, la Miséricorde (MISERICordia), qui donne à boire de la main droite, à manger de la main gauche [fig. 5]. Elle accueille un voyageur, un homme nu reçoit un vêtement, à ses pieds sont représentés un malade alité et un prisonnier. Il s'agit des six œuvres de la miséricorde, telles que Jésus les a énumérées : "Venez les bénis de mon Père ... J'ai eu faim et vous m'avez donné à manger; j'ai eu soif et vous m'avez donné à boire; j'étais un étranger et vous m'avez recueilli; nu et vous m'avez vêtu; malade et' vous m'avez visité; en prison, et vous ètes venu à moi" (Matthieu XXV, 34-36). Pierre de Blois les rappelle en une ligne dans ses vers "Sur la pénitence»: Vestio, polo, cibo, lectum do, visito, solvo ${ }^{198}$. Ce vers sera modifié au XıII ${ }^{\mathrm{e}}$ s. pour y inclure une septième œuvre, la sépulture des morts ${ }^{199}$. Le vers gravé sur l'arcade trilobée rappelle la vertu rédemptrice du secours porté aux malheureux :

DAT VENIAM SCELERI PER OPES INOPUM MISERERI

«Employer ses richesses pour secourir ceux qui sont sans ressources procure le pardon pour le crime",

avec la même formule que dans les autres scènes, hexamètre léonin riche et recherche de répétition (opes, inopum). Au-dessus de la scène le prophète Isaïe (YSAIAS PRopheta) tient une longue banderole sur laquelle on lit: FRANGE ESURIENTI PANEM TUUM, ET EgENOS VAGOSQUE INDUC IN

192. Victor SAXer, Le culle de Marie-Madeleine en Occident des origines à la fin du moyen age, Auxerre/Paris, I, 1959. p. 2-6. L'Église d'Orient a maintenu la diversité des "Marie».

193. Ibid.. I, p. 82 et $145 ;$ II, 1959, p. 223.

194. P.L., 1, c. 1211.

195. Ibid., 49, c. 1160.

196. Ibid., 111, c. 134 .

197. Ibid., 39, c. 1550, Augustin cite à ce propos Actes II, 37.

198. Ibid.. 207. c. 1156. Ce vers est cité, sans identification, par Léopold Hravifux. Les fabulisles latins depuis le siècle d'Auguste jusqu'à la fin du moyen age. IV. Paris. 1896. p. 352. Cette scéne des fonts d'Hildesheim est mentionnée par DinRon, "Les cuvres de miséricorde", Annales archéologiques, XXI, 1861, p. 195-209.

199. Hervieux, op. cit. n. 198, IV. p. 352 : Colligo, polo, cibo, solvo, lego. visito. condo. 
Doмuм тсAм, "Partage ton pain avec l'affamé, et conduis en ta maison les pauvres et les vagabonds" (Isaïe LVIII, 7), verset qui se poursuit : "couvre celui qui est nu", et qui est donc bien choisi pour annoncer le discours de Jésus sur les bonnes œuvres qui méritent le salut. Le vers du bord de la cuve dit bien que "cette œuvre de piété devient baptème".

Augustin traitant de la rémission des péchés et du baptème des jeunes enfants, souligne que "les œuvres de miséricorde sont des remèdes pour détruire les péchés " $2(0)$, ce que reprend Cassien dans des termes voisins ${ }^{201}$. Théodulphe d'Orléans indique que le baptème ne peut ètre répété, mais que les péchés commis après le baptême peuvent ètre effacés "par les larmes de pénitence, les aumônes et autres bonnes cuvres" 20?? Raban Maur, est, dans le De universo, un des rares auteurs à comprendre "les bonnes œuvres et les aumônes" dans les différents "genres de baptème" 203. La composition quaternaire des fonts baptismaux d'Hildesheim imposait ce recours à ce quatrième genre de baptème, mais du coup on peut moins clairement que pour les autres genres mettre en rapport scènes de la cuve et du couvercle. Tout au plus notera-t-on ici quavec Josué la longue errance du peuple d'Israël dans le désert s'achevait par l'entrée dans la Terre promise, qu'avec les œuvres de miséricorde on est dans l'annonce que Jésus fait de l'avènement des derniers jours : "Quand le Fils de l'homme viendra dans sa gloire" (Matthieu XXV, 3 et ss), et que ces scènes correspondent au dernier fleuve, à la dernière vertu cardinale, au dernier évangéliste. Mème si le baptême par les œuvres de miséricorde est rarement évoqué, il devait sans doute être compris par les clercs, et l'on ne s'étonnera pas de voir les six œuvres de miséricorde représentées dans un baptistère, celui de Parme, avec l'inscription d'un vers pour chaque œuvre 204 . Les œuvres sont aussi représentées avec de nombreuses inscriptions, sur la chàsse de Saint-Servais de Maastricht, en liaison avec le chapitre XXV de Matthieu ${ }^{205}$. Là le message est une invitation à la charité pour mériter la vie éternelle, et ce message est peut-être aussi, pour une part, compris dans la représentation des fonts baptismaux d'Hildesheim.

Pour se limiter à l'étude des inscriptions il faut souligner l'importance de l'écrit dans le programme des fonts baptismaux de la cathédrale d'Hildesheim. Il accompagne chaque figure, chaque scène. On a mème noté les noms des vertus, alors qu'elles sont identifiées par leurs attributs, des évangélistes alors qu'ils sont représentés par leurs symboles. Il y a une citation d'Horace, onze citations de l'Ancien Testament - dont deux à partir du Nouveau Testament neuf du Nouveau Testament. Cinq personnages sont identifiés dans le champ. Tous les commentaires sont en vers.

Les inscriptions sont parfaitement présentées dans le cadre qui leur est réservé et en rapport aver l'iconographie. Il a fallu, pour l'obtenir, une préparation rigoureuse. La calligraphie est de qualité, la gravure profonde. L'écriture est marquée par le développement et l'élégance des onciales, un

200. P.L., 44, c. 152.

201. Ibid., 49, c. 1160.

202. Ibid.. 105, c. 233 (Liber de ordine baptismi)

203. Ibid., 111, c. 133-134.

204. Geza de Fravcovich. Benedetto Antelami archiletto e scultore e l'arte del suo tempo. Milan/Florence. 195:2. I. p. $169-170$ :

1. (Juxta hoc exemp) LCM PEREGRINIS HOSTIA PANDAS

2. CLU MLLTA CLRA LAVAT IIIC EGRO SIA CRIRA

3. ESCA.M LARGA MANES HEC PORRIGIT ESLRIENTI

4. HIC QLOJ QLESIERAT SICIENTI POCLLA PRESTAT

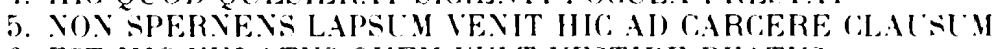

6. EST HIC NUDATLS OLEM VILT VESTIRE BEATLS

205. Renate Kroos, Der Schrein des heiligen Servatius in Maastrich und die vier augehörigen Reliquiare in Brüssel. Munich, 1985) : les bonnes auves (bona opera) occupent les deux versants du toit du reliquaire. Inscript ions p. 1.41-1.15. at pl. 15. 17. 45. 46. qui illustrent le chapitre XXV de Matthieu. 
véritablement "fleurissement" de certaines lettres (le $C$ de crimine sur la cuve, le dernier $A$ de facla sur le couvercle notamment); des redoublements de traits, avec des hachures entre les deux traits dans de nombreuses lettres. Bien des $M$ et des $N$ se terminent par un crochet caractéristique (IBOPVOr). La beauté de l'écriture participe à la beauté de l'œuvre. L'écriture peut être datée de la première moitié du xıIr. s., mais pour une datalion plus serrée il faudrait disposer d'éléments de comparaison pour la région.

La langue a fait aussi l'objet d'une recherche évidente. On pourrait presque dire que le style est quelque peu précieux, tout comme l'écriture tend vers un certain "baroque». Dans les vers qui présentent l'ensemble du programme au bord supérieur de la cuve on a des versus caudali. c'est-àdire les mêmes rimes dissyllabiques dans deux vers consécutifs, et il en est de même pour les quatre vers qui accompagnent les quatre fleuves du paradis à la base de la cuve. Dans les grandes scènes on a aussi des hexamètres en versus caudali pour le passage de la mer Rouge et la traversée du Jourdain par Josué, mais des vers léonins riches pour les deux autres grandes scènes, et mème, pour les vers de la scène de donation des rimes riches identiques aux hémistiches et aux finales (versus unisoni). Au bord supérieur de la cuve il y a jeu évident entre la finale mundum, "monde", et mundum, "pur". Les huit vers du couvercle sont des hexamètres léonins riches, avec une recherche constante d'effet par les répétitions de mots de même étymologie ou de mème son (mundat, immunda, unda; juste, fusus, usus; laval, lacrimis; virga, viget, vigente; cruor, crudele, cruental; reficit, refectus; opes, inopum). Seul le dernier vers du bord de la cuve échappe à cette pratique.

Le programme est bâti à partir du chiffre quatre. Cela va parfois de soi, comme pour les fleuves du paradis, les vertus cardinales, les grands prophètes, les évangélistes. Mais on ne trouve pas ailleurs le rapport fleuves-vertus-prophètes-évangélistes, alors que souvent on a joint fleuves, vertus et évangélistes. L'adjonction des prophètes est ici une construction propre à l'auteur du programme. De même il a présenté seulement trois figures du baptême et complété la quaternité par la scène de donation. De même il a enrichi la trilogie habituelle des genres de baptême, pour y joindre le baptème par les bonnes œuvres, qui est rarement exprimé par les auteurs. Il a poussé la recherche jusqu'à mettre des correspondances entre les scènes de la cuve et celles du couvercle, seules les deux dernières scènes, passage du Jourdain par Josué et œuvres de miséricorde n'ayant pas un rapport évident. On remarquera que l'auteur a évacué la tradition la plus ancienne et la plus classique du chiffre huit pour les fonts baptismaux tels que ceux de Saint-Ambroise à Milan :

OCTAGONLS FONS EST MUNERE DIG.NLS EO
HOC NCMERO DECLIT SACRI BAPTISMATIS ALLAM 206

de Saint-Jean de Latran à Rome, ou encore d'Albenga, Cividale, Ravenne, Parenzo, etc.

À partir de l'iconographie et avec l'aide des inscriptions on a un véritable "traité" sur le baptème. L'auteur présente plusieurs figures du baptème, comme on le faisait dans la catéchèse baptismale des catéchumènes : baptême du Christ par Jean, qui s'imposait, passage de la mer Rouge, figure la plus fréquente, déjà consacrée par le Nouveau Testament, passage du Jourdain par Josué, ce qui est moins fréquent que d'autres figures mais permettait une représentation iconographique parallèle à celle du passage de la mer Rouge. Il a aussi traité des différents genres de baptême. Le premier genre, le baptême par l'eau, est celui qui est le moins clairement exprimé, parce que l'auteur a voulu en même temps mettre en correspondance la verge qui sort de l'arbre de Jessé et le bâton d'Aaron. Les baptêmes du sang et de la pénitence ont leur parfaite corrélation avec les scènes de la cuve, parfaite du moins si on connaît l'interprétation habituelle des auteurs ecclésiastiques pour la couleur de la mer Rouge. Le baptême par les œuvres de miséricorde, c'est-à-dire le salut assuré par la pratique de la charité, illustre le chapitre 25 de Matthieu et les paroles de Jésus 
sur le Jugement dernier. Les fonts baptismaux d'Hildesheim comportent un enseignement sur les grâces du baptême. D'abord le baptisé est libéré du péché, et de tous ses péchés. Le "cœur est libéré du péché", le Christ "a libéré son peuple de ses péchés", "par le Christ dans le baptème nous fuyons les ténèbres des vices", et sur le couvercle, "l'eau du saint baptême purifie", les autres genres de baplême lavent du péché (lavachrum, lavat). La demande de pardon à l'occasion des cuvres de miséricorde (dat veniam) rejoint la demande de pardon du donateur (venie spe dat). Cette purification demande une attitude de pénitence. Le baptisé renonce à Satan et à ses œuvres. Les péchés sont remis à la femme pécheresse parce qu'elle s'en repent dans les larmes (a flente), par une confession avec larmes (lacrimis confessio). En second lieu le baptême ouvre le chrétien à une vie nouvelle, et lui donne accès à la vie éternelle. Fleuves du paradis, vertus cardinales, Évangiles irriguent le monde à partir du Christ "source de vie». "Par Lui le baptême est pour nous sanctifié». Par cette même source, Dieu, et sous sa conduite, nous sommes entraînés "vers la vie», à l'image de Josué entrant en la Terre promise. Cette double idée de purification des péchés et de rénovation, "renaissance" du baptisé (renatus) "07, se trouve superbement exprimée dans les inscriptions du baptistère du Latran à Rome, mais aussi dans les mosaïques de l'ancien baptistère de Tipsa en Algérie :

SI QLIS, UT VIVAT, QLAERIT ADDISCERE SEMPER

hic lavetur aQua, et Videat caelestia regna,

ou encore dans les inscriptions des baptistères de Saint-Pierre de Rome :

SOLVERE QUI POTUIT CAELO TERRAQUE LIGATA

CRIMINA, FONTE SACRO RENOVAT MORTALIA MEMBRA,

ou de Saint-Paul-hors-les-Murs :

HAEC DOMUS FST FIDFI, MENTES I:BI SIMMA POTESTAS

LIBERAT, ET SANCTO PURGatas FONTE TLETLR ${ }^{208}$.

Elle est aussi signifiée en une belle formule par l'inscription des fonts baptismaux de la cathédrale d'Osnabrück: + xam redit ad vitay noves et vetes interit adam ${ }^{209}$. À Hildesheim l'abondance des textes fait perdre un peu de sa force à ce qui est ailleurs exprimé en formules "lapidaires", mais l'auteur du programme ouvre en même temps des pistes pour que le baptisé soit vraiment l'homme "nouveau" que cite l'inscription du baptistère du Latran : la pratique des vertus cardinales, les ceuvres de miséricorde, et par-dessus tout la marche à la suite de Celui qu'ont annoncé les prophètes et dont les évangélistes ont rapporté l'Incarnation, la Passion, la Résurrection et l'Ascension. Cette ceuvre savante du milieu canonial d'Hildesheim demande à ètre

207. NISI QLIS RENATIS FLERIT EX AQLA FT SPIRITL NON POTEST I.NTROIRE IN RE(BNLY IDEI, citation de l'évangéliste Jean (III. 5) inscrite sur une croix de Liessies (Nord). vers 116(1-117) (Lart roman. Calalogne.... Barcelone, 1961, p. 261-262. $\left.n^{\prime \prime} 4133\right)$.

208. Robert Favreac. "L "̈ppigraphie comme source pour la liturgie". dans Iom Quellenuert der Inschriften. Vorträge

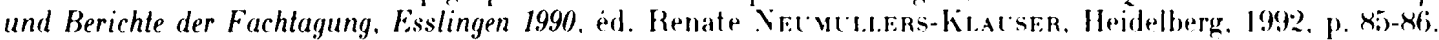

209. Die Inschriften der Stadt Osnabrüch, èd. S. Wвнкім;. p. ४. п. 9. 
longuement méditée, comme on le ferait d'un traité sur le baptème. Elle appelle, au-delà de l'admiration que l'on ressent devant sa beauté esthétique, un profond regard intérieur.

Fiat ut interius quod fil el exterius (fonts baptismaux de Merseburg, 1200). Et pour sa compréhension en profondeur les inscriptions qui l'accompagnent sont un guide incomparable et indispensable.

* Robert FAVREAL C.É.S.C.M.

24. rue de la Chaìne F-86022 POITIERS 